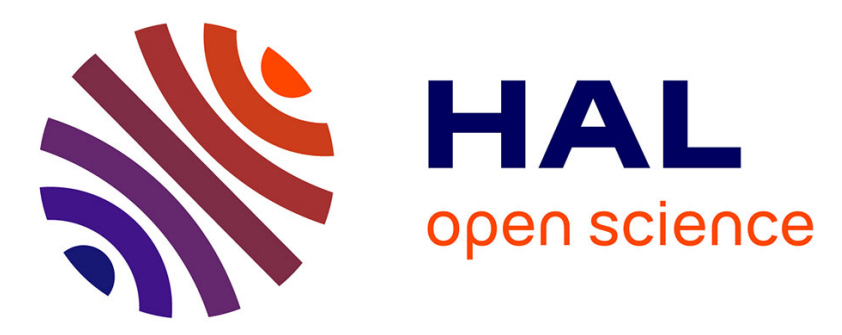

\title{
A decision tree framework to support design, operation, and performance assessment of constructed wetlands for the removal of emerging organic contaminants
}

\author{
Huma Ilyas, Ilyas Masih, Eric D. van Hullebusch
}

\section{- To cite this version:}

Huma Ilyas, Ilyas Masih, Eric D. van Hullebusch. A decision tree framework to support design, operation, and performance assessment of constructed wetlands for the removal of emerging organic contaminants. Science of the Total Environment, 2021, 760, pp.143334. 10.1016/j.scitotenv.2020.143334 . insu-03188601

\section{HAL Id: insu-03188601 \\ https://hal-insu.archives-ouvertes.fr/insu-03188601}

Submitted on 2 Apr 2021

HAL is a multi-disciplinary open access archive for the deposit and dissemination of scientific research documents, whether they are published or not. The documents may come from teaching and research institutions in France or abroad, or from public or private research centers.
L'archive ouverte pluridisciplinaire HAL, est destinée au dépôt et à la diffusion de documents scientifiques de niveau recherche, publiés ou non, émanant des établissements d'enseignement et de recherche français ou étrangers, des laboratoires publics ou privés. 


\section{Journal Pre-proof}

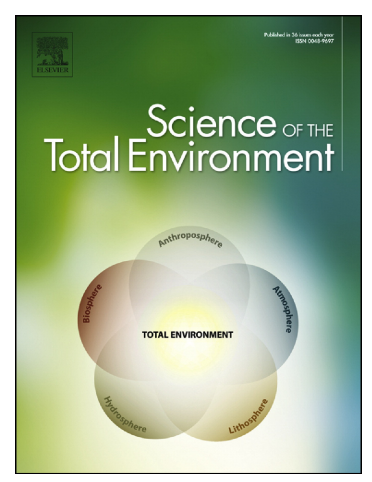

Huma Ilyas, Ilyas Masih, Eric D. van Hullebusch

A decision tree framework to support design, operation, and performance assessment of constructed wetlands for the removal of emerging organic contaminants

PII: $\quad$ S0048-9697(20)36865-0

DOI: $\quad$ https://doi.org/10.1016/j.scitotenv.2020.143334

Reference: $\quad$ STOTEN 143334

To appear in: $\quad$ Science of the Total Environment

Received date: $\quad 15$ August 2020

Revised date: $\quad 23$ October 2020

Accepted date: $\quad 24$ October 2020

Please cite this article as: H. Ilyas, I. Masih and E.D. van Hullebusch, A decision tree framework to support design, operation, and performance assessment of constructed wetlands for the removal of emerging organic contaminants, Science of the Total Environment (2020), https://doi.org/10.1016/j.scitotenv.2020.143334

This is a PDF file of an article that has undergone enhancements after acceptance, such as the addition of a cover page and metadata, and formatting for readability, but it is not yet the definitive version of record. This version will undergo additional copyediting, typesetting and review before it is published in its final form, but we are providing this version to give early visibility of the article. Please note that, during the production process, errors may be discovered which could affect the content, and all legal disclaimers that apply to the journal pertain.

(C) 2020 Published by Elsevier. 
A decision tree framework to support design, operation, and performance assessment of constructed wetlands for the removal of emerging organic contaminants

\author{
Huma Ilyas, ${ }^{1,3^{*}}$, Ilyas Masih ${ }^{2,3}$, Eric D. van Hullebusch ${ }^{1}$ \\ ${ }^{1}$ Université de Paris, Institut de physique du globe de Paris, CNRS, F-75005 Paris, France \\ ${ }^{2}$ IHE Delft, Institute for Water Education, 2611 AX Delft, The Netherlands \\ ${ }^{3}$ Water Treatment and Management Consultancy, B.V., 2289 ED Rijswijk, The “etherlands \\ * Corresponding author email: hi.wtmconsult@gmail.com
}

\title{
Abstract
}

There is an increasing focus on research related to removal of emerging organic contaminants (EOCs) from wastewater by using construc ${ }^{+} \Omega^{\top} w{ }^{\wedge}$ tlands (CWs). However, research is lacking on translating the available scientific evidence into decision support tools. In this paper, a novel decision tree framework is develope 1 . nd demonstrated. The proposed framework consists of five steps: (1) generate a list of E: Cs jy the analysis of the wastewater; (2) select the best type of CW for each of the selecte' EOCs; (3) select a final type of CW for the removal of the selected EOCs; (4) id nti v d tailed design and operational features of the proposed CW such as, depth, area, plants, sup $\sim$ rt matrix, hydraulic loading rate, organic loading rate, and hydraulic retention time; and (5) assess the expected removal efficiency of EOCs in the selected CW. A novel decision support tool, named as DTFT-CW, was developed to generate data and information for the application of the proposed decision tree framework. DTFT-CW (given as a supplementary material) was developed using Microsoft Excel 2016 to support decisions on the design, operation, and performance of CWs for the removal of 59 EOCs (33 pharmaceuticalsPhCs, 15 personal care products-PCPs, and 11 steroidal hormones-SHs). The paper demonstrates 
the usefulness of the developed decision-making tools by considering 19 EOCs (13 PhCs, one PCPs, and five SHs) as an example, which pose high environmental risk and are on the European Union watch list (six of the 19 EOCs). An integrated design of HCW (combining vertical flow $\mathrm{CW}$, horizontal flow $\mathrm{CW}-\mathrm{HFCW}$, and free water surface $\mathrm{CW}$ ) is recommended for the treatment of multiple EOCs instead of a single type of CW such as HFCW that is most widely used in practice. The proposed tools could be useful for decision makers such as policy makers, design engineers, and researchers.

Key words: Constructed wetlands; Decision tree framework, L c cision support tool; Design and operational parameters; Emerging organic contaminants ${ }^{\mathbf{n}} \mathbf{e}_{\mathbf{l}}$ ' oval efficiency.

\section{Introduction}

Constructed wetlands (CWs) are low cosı nd nature-based treatment technologies that have been extensively investigated for wa tewater treatment containing emerging organic contaminants (EOCs) such as ph $\mathbf{r n}^{\top}{ }^{\circledR}$ ceuticals (PhCs) (Carvalho et al., 2014; Li et al., 2014; Verlicchi and Zambello, 201‘ Lang et al., 2014; Gorito et al., 2017; Ekperusi et al., 2019), personal care products ( $\mathrm{CH}_{\mathrm{r}}$ ) (Verlicchi and Zambello, 2014; Zhang et al., 2014; Verlicchi et al., 2015; Vo et al., 2018) and steroidal hormones (SHs) (Töre et al., 2012; Gorito et al., 2017; Vo et al., 2018). The investigated CWs are free water surface CW (FWSCW), horizontal flow CW (HFCW), vertical flow CW (VFCW), and hybrid CW (HCW). Few experimental studies conducted the comparative analysis on the performance of different types of CWs (Supplementary materials 1: Table S1). Ilyas and van Hullebusch (2020a, 2020b, 2020c) conducted a comprehensive and critical review of the performance and a comparison of all types of CWs for the removal of these EOCs based on the available literature. These studies indicated 
compound specific and high variability in the removal efficiency of EOCs in different types of CWs. There are several factors responsible for the variable performance of CWs such as design and operational features of CWs, and physicochemical properties of EOCs.

Several individual studies have examined the effect of plants in CWs by considering the removal of EOCs in planted and unplanted CWs as summarized in Table S2, given in supplementary materials 2. The role of support matrix in the removal of EOCs have been explored by several authors as well (Table S2). The role of operational factors such is i varaulic loading rate (HLR), organic loading rate (OLR), and hydraulic retention time HR ) has been explored by some researchers (Table S2). A detailed statistical analysis to $1 \mathrm{n}$ v ssigate the correlation of design and operational parameters of CWs such as depth, ara, HLk, OLR, and HRT with the removal efficiency of EOCs was conducted by Ilya ${ }^{2} \mathbf{l}^{\top}{ }^{\top}$ van Hullebusch $(2019,2020$ c, 2020d). These studies indicated that the design and operatı al parameter are very important governing factors in CWs performance for the removal , I :OCs.

While several experimental and syn hesis (review) studies have been conducted on the removal of EOCs by CWs, the resu $\cdot \mathrm{rc}^{\prime} 1$ is lacking on translating available scientific evidence into decision-making tools. $\urcorner_{n_{1}}$ a few studies have attempted to develop decision support systems (DSS) to support design and operation of CWs (Turon et al., 2007; Reyes-Contreras et al., 2012; Sultana et al., 2015). Turon et al. (2007) developed a novel environmental decision support system (EDSS) to improve the operation and maintenance of widely used HFCW (EDSSmaintenance). The EDSS provides a comprehensive guideline to facilitate design engineers and operation managers to sustain the performance of $\mathrm{CWs}$ in general, although no reference is made to the performance of CWs for the removal of EOCs. Sultana et al. (2015) used decision tree 
approach for designing CWs (FWSCW, HFCW, and VFCW) with the focus on the removal of conventional parameters (chemical oxygen demand, biochemical oxygen demand, total suspended solids, total nitrogen, and total phosphorus). Reyes-Contreras et al. (2012) used a regression tree approach for the removal efficiency of the 10 EOCs (PhCs and PCPs) and the decision factors were vegetal species (Typha angustifolia, Phragmites australis or unplanted), kind of substrate (soilless, free-water layer or gravel), flow type (surface or subsurface flow), season (summer or winter), and age of the system (expressed in - amesters). Furthermore, the novel predictive models, in the form of multiple linear resas ins, were developed for the removal efficiency of EOCs in CWs based on their phy. ${ }^{-}$cochemical properties (Ilyas et al., under review in Journal of Environmental Management, , and design and operational parameters of CWs (Ilyas et al., 2020a). The proposed modrls or ld serve as screening tools to gain insights about the removal efficiency of a certain $\Gamma{ }^{\wedge} \mathrm{C} P \mathrm{PCP}$, and $\mathrm{SH}$ in $\mathrm{CWs}$.

Although the developed tools and madt: are useful to serve their intended purposes, these studies indicate very limited rese arc: un developing integrated decision support tools (DSTs) that can provide sound scienticic information on various important questions in decision-making process on the design, pe atıon, and performance of CWs for the removal of EOCs. For example, what type of $\mathrm{Ch}$ would be more suitable for a certain list of EOCs in a given context?; what could be the suitable design and operational parameters of CWs for the removal of EOCs under consideration?; what could be the expected performance of CWs for the removal of EOCs under consideration? The development of tools to answer such questions could be very useful to provide sound scientific basis for multiple decision makers such as CW design engineers and operational managers, policy makers, and researchers. 
Therefore, more research is needed to develop comprehensive and integrated DSTs with specific focus on EOCs removal by CWs. This research aims at the development of a novel DST to support design, operation, and performance assessment of CWs for the removal of EOCs. The specific objectives are: (1) to develop a decision tree framework to support design and operation of CWs for the removal of EOCs; (2) to develop a DST to provide a quick overview of the information required in different steps proposed in the decision tree framework; and (3) to demonstrate the application of the developed DST using the seluted EOCs, which pose high environmental risk and are on the European Union (EU) watch ${ }^{1}{ }_{\text {is.. }}$

\section{Methodology}

A novel decision tree framework is developed $\therefore$ d applied in this study (Figure 1). A brief

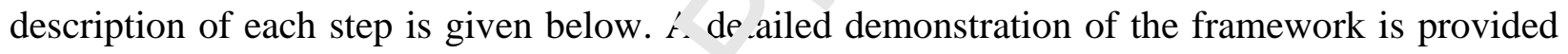
in the results and discussion section by $\mathrm{u}_{\llcorner}$ing an example of selected EOCs, which are on the EU watch list as per EU decision 2015'195 r 3 U, 2015; Barbosa et al., 2016; Gorito et al., 2017) and EU decision 2018/840 (EU, ¿118; Loos et al., 2018), and those categorized under high environmental risk categr $\because$ as et al., 2020b, Ilyas and van Hullebusch 2020b, 2020c). The proposed approach cons. ${ }^{+} \mathrm{s}$ of five steps where certain analysis is carried out and decisions are taken based on the available data/information (Figure 1). The first step involves the analysis of the wastewater to be treated, in particular with respect to types of EOCs present in it besides examining conventional parameters. Once the wastewater composition is examined, a list of EOCs can be generated, which should be considered in the wastewater treatment process. It is prudent to gather more (relevant) information about the selected EOCs, for example about their environmental risk, physicochemical properties, and removal efficiency in different types of 
CWs. In the second step, the best type of $\mathrm{CW}$ is selected based on the available scientific evidence on EOCs according to their removal mechanisms (e.g., biodegradation-aerobic and/or anaerobic, adsorption and/or sorption, uptake by the plants, and photodegradation). This process is carried out for all the selected EOCs. The third step is about making a final selection on the CW system. There could be different options to select the type of CW. For example, a simple approach could be to select the type of CWs that is best suited for the removal of most of the selected EOCs. Another option could be to select an integrated des: on if more than one type of CWs are suitable to remove the selected EOCs. For example, s s.ection of HCW system (e.g., combining FWSCW, VFCW, and HFCW) could be recon. nended for the treatment of multiple types of EOCs because such a system can better pro ide necessary conditions of different removal mechanisms. In the fourth step, a dev."ier design and operational features of the proposed CW system are identified. The $:$ r.e several design and operational parameters that could be considered in this analysis sucı רs, depth, area, plants, support matrix, HLR, OLR, and HRT. The values of these paramete- cid be accumulated from available scientific evidence. In the fifth step, an overview oi the expected performance of the proposed CWs system is presented. The expected $r_{11}$ of performance could be based on the synthesis of the experimental studies (e.s Ilyas et al., 2020b, Ilyas and van Hullebusch, 2020a, 2020b, 2020c) and prediction through multiple linear regression models (e.g., Ilyas et al., 2020a; Ilyas et al., under review in Journal of Environmental Management). The fifth step is complete when the expected performance is acceptable, otherwise, the users may repeat part or all of the steps in the decision tree framework with the aim to achieve better results (if possible). 
A new tool was developed to readily provide data and information required in each step of the decision tree framework. The salient features of the tool are described in the results and discussion section. 


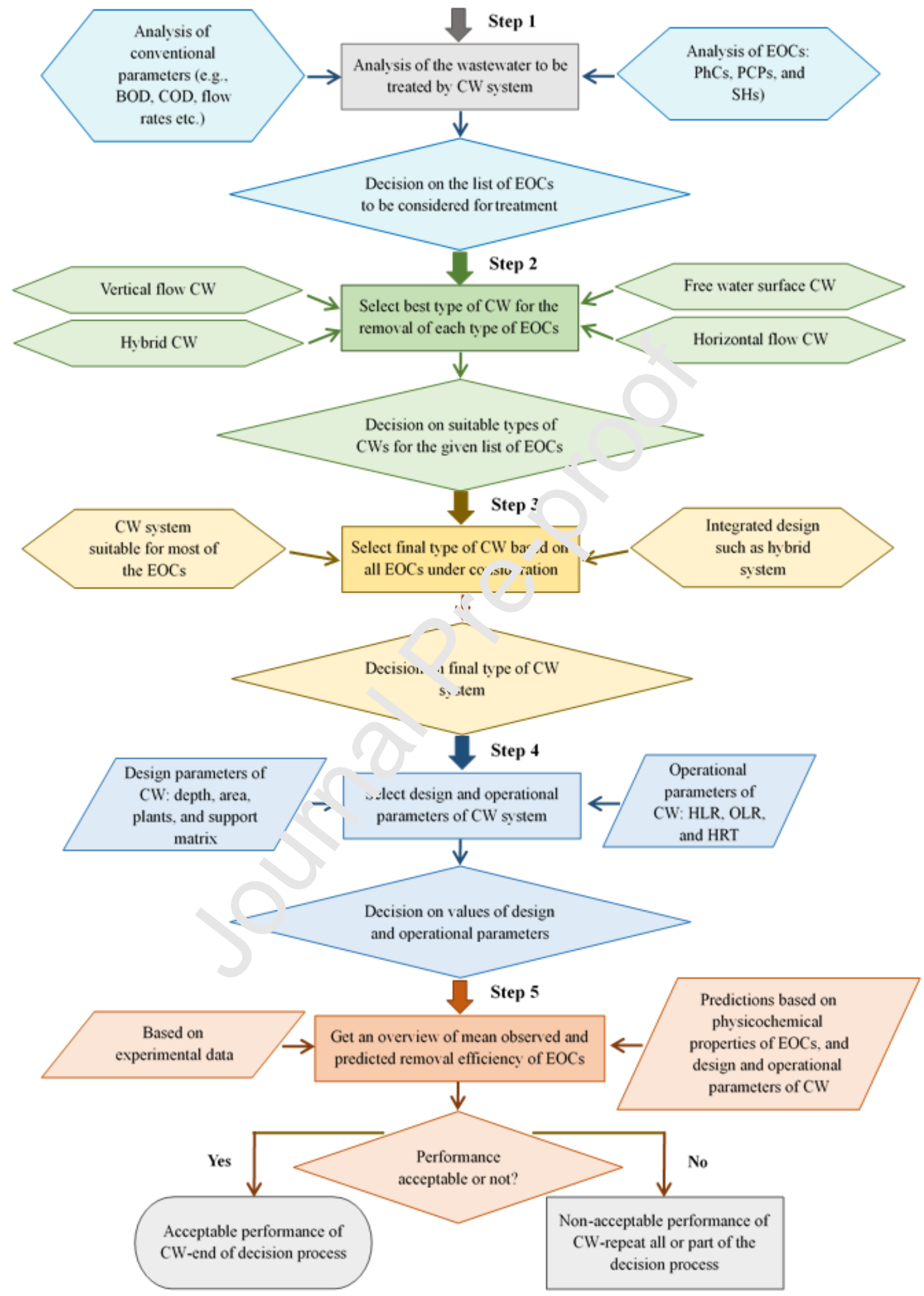

Figure 1. A schematic illustration of the steps involved in decision tree approach. 


\section{Results and discussion}

\subsection{Development of a novel data and information management tool}

\subsubsection{DTFT-CW}

The key features of the novel DST, referred hereafter as DTFT-CW, developed in this research are schematized in Figure 2 and briefly described below. DTFT-CW was developed using Microsoft Excel 2016, and is provided as a supplementary matei:? (Excel file: DTFT-CWsecure, along with the user manual).

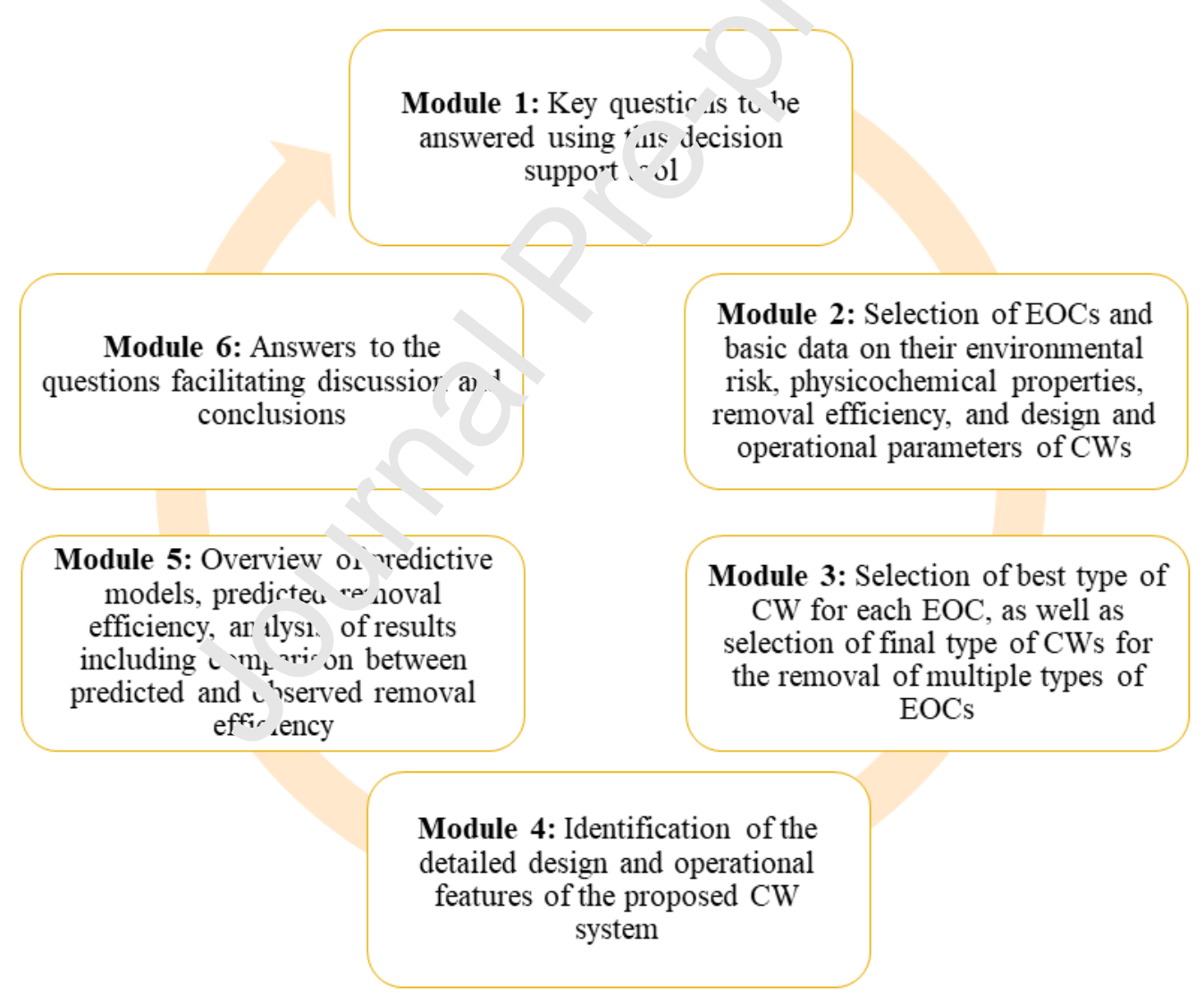

Figure 2. A schematic diagram illustrating the modules of the developed DTFT-CW. 


\subsubsection{Modules in DTFT-CW}

The proposed DTFT-CW is composed of six modules, which could be followed sequentially. DTFT-CW can be used by an individual user or multiple users in the form of a group of different stakeholders (e.g., policy/decision makers, wastewater managers, design engineers and operators of CW systems, researchers/scientists, and citizens).

\subsubsection{Module 1}

The first module displays the basic set up of DTFT-CW and c onta ns the list of key questions that could be explored using the tool. These questions are $a_{1}$ on $\mathrm{d}$ to facilitate decision making process for each of the five decision steps outlined is the decision tree framework (Figure 1). The key questions are enumerated below.

1. What are the EOCs to be considered $\mathrm{fr}$ : th CWs design and operation?

2. What is the potential environmental $\mathrm{r}_{\mathbf{n}} \mathrm{k}$ posed by the EOCs under consideration?

3. Which types of CWs are suitat le irr the removal of each EOC under consideration?

4. Which type of $\mathrm{CW}$ coula be recommended for the removal of selected EOCs under consideration?

5. What are the plausibie range of values of $\mathrm{CW}$ design and operational parameters?

6. What is the expected removal efficiency of selected EOCs for the finally selected CWs design and operational parameters?

\subsubsection{Module 2}

The second module involves the analysis of the wastewater to be treated, with respect to types of EOCs. Once the wastewater composition is examined, a list of EOCs can be generated, which 
should be considered in the wastewater treatment process. This module contains the list and basic data of the 59 EOCs (33 PhCs, 15 PCPs, and $11 \mathrm{SHs}$ ) (Supplementary materials 3: Table S3) including their names, environmental risk, physicochemical properties, and removal efficiency in four types of CWs (FWSCW, HFCW, VFCW, and HCW), and data on design and operational parameters of these four types of CWs. The data was compiled from the peer reviewed published sources in our previous work (Ilyas et al., 2020b; Ilyas and van Hullebusch, 2019, 2020a, 2020b, 2020c, 2020d). In this module, the user wili select specific EOCs to be examined. In case DTFT-CW is used by multiple stakeholde- $\quad$ - - y need to agree on the final list of EOCs to be examined. After selecting the EOCs frow the given list, the tool automatically does the required calculations to answer the key questı.. The answers to these questions are presented under module 6 and are ready for th $\mathrm{r}$ view soon after the EOCs are selected. However, it is recommended that the use. $g$, through all modules (3-6) in a sequential way to

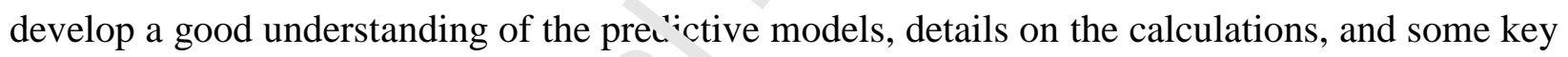

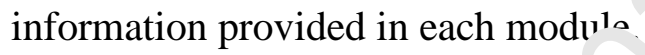

\subsubsection{Module 3}

In the third module, tis $-\mathrm{b}$, st ${ }^{+} \mathrm{ype}$ of $\mathrm{CW}$ is selected based on the available scientific evidence on EOCs according to their removal mechanisms (biodegradation-aerobic and/or anaerobic, adsorption and/or sorption, uptake by the plants, and photodegradation). This process is carried out for all the EOCs. The information used in this process is compiled in our previous work (Ilyas et al., 2020b; Ilyas and van Hullebusch, 2020a, 2020b, 2020c). This module also involves the decision about the final selection on the $\mathrm{CW}$ system. There could be several options to select the type of CW. For example, in case of 59 EOCs included in DTFT-CW, HCW appears to be best option for 21 out of 59 studied EOCs. Thus, one option could be to select HCW in this case 
(Supplementary materials 4: Figure S1). Whereas VFCW, HFCW, and FWSCW are the best alternatives for 17,14 , and 7 of the 59 EOCs under consideration, respectively. This highlights the need of integrated design of HCW that should contain features of all the three CW types: VFCW, HFCW, and FWSCW.

\subsubsection{Module 4}

In the fourth module, detailed design and operational features of the proposed $\mathrm{CW}$ system are identified. There are several design and operational parameters tha' could be considered in this analysis such as depth, area, HLR, OLR, HRT, plants, and ups ort matrix. The values of these parameters are taken from our previous work (Ilyas t al., 2020a, 2020b; Ilyas and van Hullebusch, 2019, 2020c, 2020d), which could snve as initial guide in the decision-making process on design and operation of the seler ${ }^{+\wedge}$. TW system. The mean and standard deviation in the case of depth, area, HLR, OLR, and Hk ${ }^{\top}$ and best-count in the case of plants and support matrix are provided based on severa' a 'allable studies to support the decision on the plausible range of values of these variables In this module the design and operational parameters of four types of CWs are summarized : 7 sed on available scientific evidence related to all the 59 EOCs included in the tool $(\mathrm{Tabl}: 1)$.

\subsubsection{Module J}

The fifth module is composed of the novel predictive models, which are developed in our previous work (Ilyas et al., 2020a; Ilyas et al., under review in Journal of Environmental Management). In these studies, we have developed several plausible models for predicting removal efficiency of EOCs based on physicochemical properties of EOCs, and design and operational parameters of CWs (see Supplementary Excel file: DTFT-CW-secure). These models 
were developed in the form of multiple linear regressions after detailed statistical analysis of data by applying principle component analysis and Pearson correlation. Details on all the plausible models are given in DTFT-CW in the sheets of Models_Phys_Chem Properties and Models_Design \& operations. These best performing models were selected by following a rigorous statistical evaluation criterion composed of five indicators: root mean square error (RMSE) (lower the RMSE better the model), the difference between observed and simulated removal efficiency (lower the better), coefficient of determinaw $n\left(R^{2}\right)$ (higher the better), probability ( $p$ ) value (lower the better), and the number of prdicints in the equation (lower the better). The observed and predicted removal efficiencie of 59 studied EOCs are shown in Figures 3-5 in the case of $\mathrm{HCW}$ that emerges as the bes. oystem to treat wastewater containing multiple types of EOCs. The mean values of sirnu' ${ }^{1}$ te $\perp$ and observed removal efficiencies are in close agreement in most cases. For $e^{\prime} \mathrm{m}$, le, the difference between mean observed and predicted removal efficiency was less 2 'an $20 \%$ in the case of 28 out 44 EOCs (64\% of the examined EOCs) for which the obs ${ }^{\sim} \mathrm{ve}^{\mathcal{1}}$ data were available. The model performance in terms of RMSE values was very good in . nost cases (RMSE training sets: 3-16\%; test sets:11-28\%).

Moreover, Figures 3-5 sl ow nean and standard deviation to include the uncertainty range in the observed and predicted re noval efficiency. The analysis reveals that standard deviation is quite high in the case of observed removal efficiencies of EOCs (Figures 3-5). This indicates considerable differences in removal efficiencies under different environmental, design, and operational conditions of CWs. On the other hand, the mean of predicted removal efficiency is in close agreement with the observed values, as it falls well within the range of standard deviation in most cases (Figures 3-5). In general, the fifth module enables further analysis of the results, mainly by comparing the predicted and observed removal efficiency in four types of CWs. This 
will help to triangulate the predictions with experimental results, which will contribute to informed decision-making process.

\subsubsection{Module 6}

The sixth module provides answers to the key questions raised in module 1 . This provides the basis of detailed discussion and conclusions that could be drawn from the study. In this module, standard answers to the questions are generated in tabular as well as graphical form, which will contribute to the discussion and decision-making process (Figur $\_1$ n decision tree framework). Finally, the users may choose to finish the session or cho ose to repeat the whole cycle (all modules) or part of it (e.g., specific modules) using new seı $x$ EOCs. 
Table 1. Design and operational parameter values derived from available scientific evidence related to all the 59 EOCs under consideration.

\begin{tabular}{|c|c|c|c|c|c|c|c|}
\hline CW type & $\begin{array}{c}\text { Depth } \\
(\mathbf{m}) \\
\text { Mean } \pm \text { Stdev }\end{array}$ & $\begin{array}{c}\text { Area } \\
\left(\mathbf{m}^{2} \mathbf{P E}^{-1}\right) \\
\text { Mean } \pm \text { Stdev }\end{array}$ & $\begin{array}{c}\text { HLR } \\
\left(\mathbf{m}^{3} \mathbf{m}^{-2} \mathbf{d}^{-1}\right) \\
\text { Mean } \pm \text { Stdev }\end{array}$ & $\begin{array}{c}\text { OLR } \\
\left(\mathrm{g} \mathrm{COD} \mathrm{m}^{-2} \mathrm{~d}^{-1}\right) \\
\text { Mean } \pm \text { Stdev }\end{array}$ & $\begin{array}{c}\text { HRT } \\
\text { (days) } \\
\text { Mean } \pm \text { Stdev }\end{array}$ & $\begin{array}{c}\text { Plant } \\
\text { Based on Best-Count }\end{array}$ & $\begin{array}{c}\text { Support matrix } \\
\text { Based on Best-Count }\end{array}$ \\
\hline FWSCW & $0.85 \pm 0.41$ & $11.71 \pm 6.53$ & $0.08 \pm 0.06$ & $15.99 \pm 21.45$ & $7.19 \pm 5.05$ & Phragmites australis & Gravel \\
\hline HFCW & $0.66 \pm 0.16$ & $6.64 \pm 2.43$ & $0.50 \pm 0.59$ & $24.03 \pm 23.38$ & $5.72 \pm 3.49$ & Phragmites australis & Gravel \\
\hline VFCW & $0.67 \pm 0.15$ & $5.47 \pm 4.14$ & $0.13 \pm 0.07$ & $32.00 \pm 17.09$ & $2.94 \pm 3.46$ & Phragmites australis & Sand \\
\hline $\mathrm{HCW}$ & $0.92 \pm 0.40$ & $6.76 \pm 3.55$ & $0.17 \pm 0.15$ & $58.22 \pm 74.19$ & $5.33 \pm 2.29$ & I hragmites australis & Gravel \\
\hline
\end{tabular}

Note: Data is taken from Ilyas et al. (2020a, 2020b); Ilyas and van Hullebusch (2019, 2020c, 2020d).

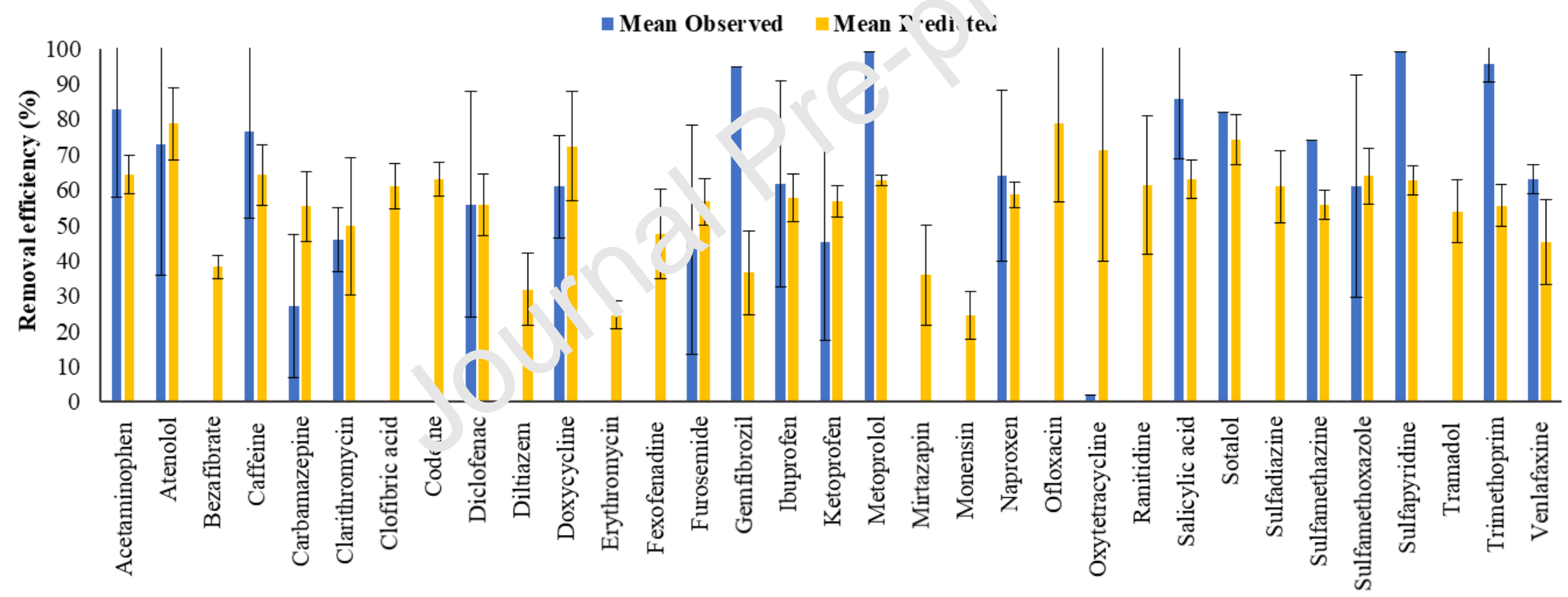

Figure 3. The expected removal efficiency of $33 \mathrm{PhCs}$ based on observed and predicted results in HCW.

Note: Standard deviation values were capped at 100 to improve the readability of the graph. Actual values can be found in DTFT-CW. 


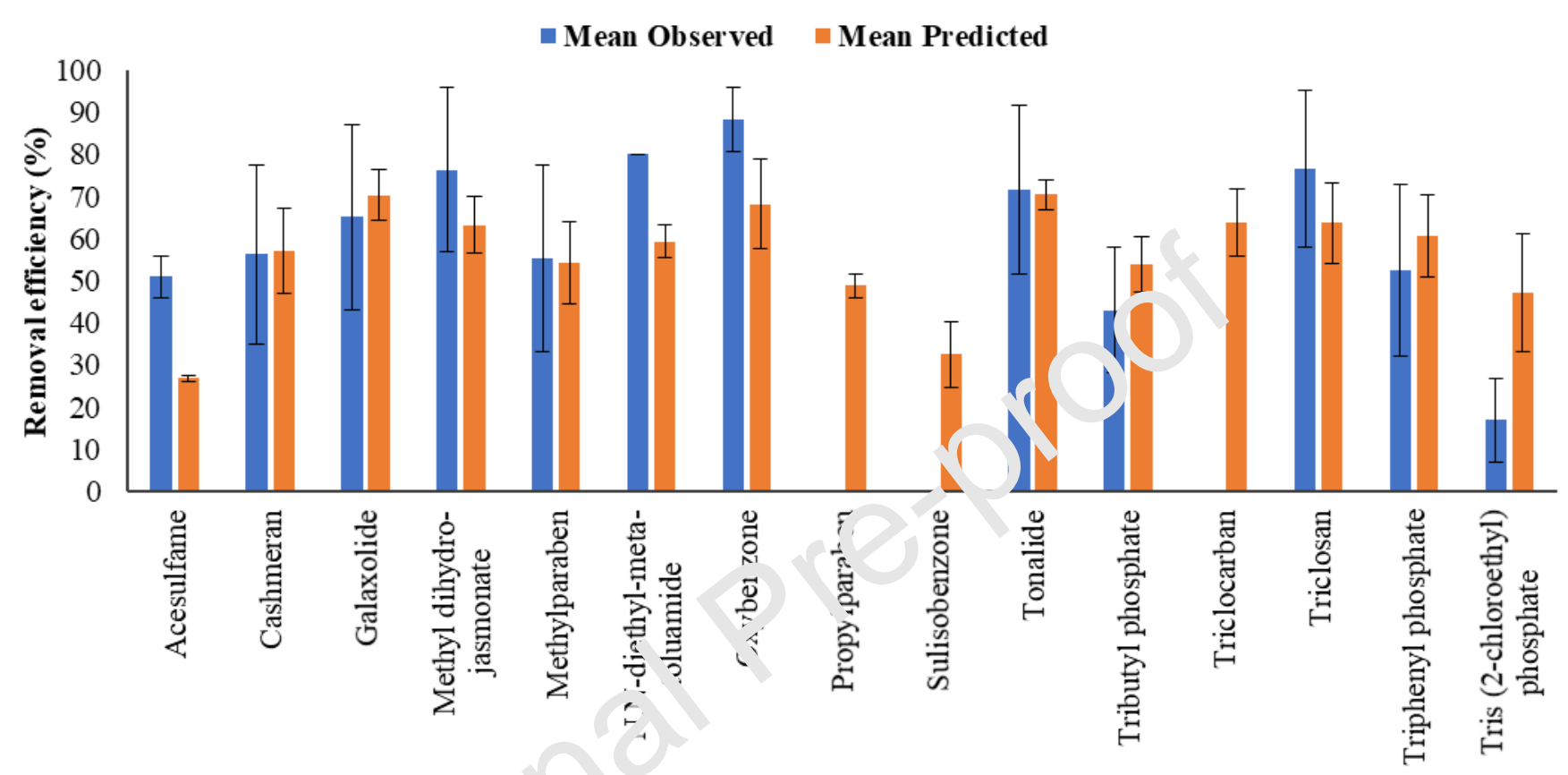

Figure 4. The expected removal effic:en of 15 PCPs based on observed and predicted results in HCW. 


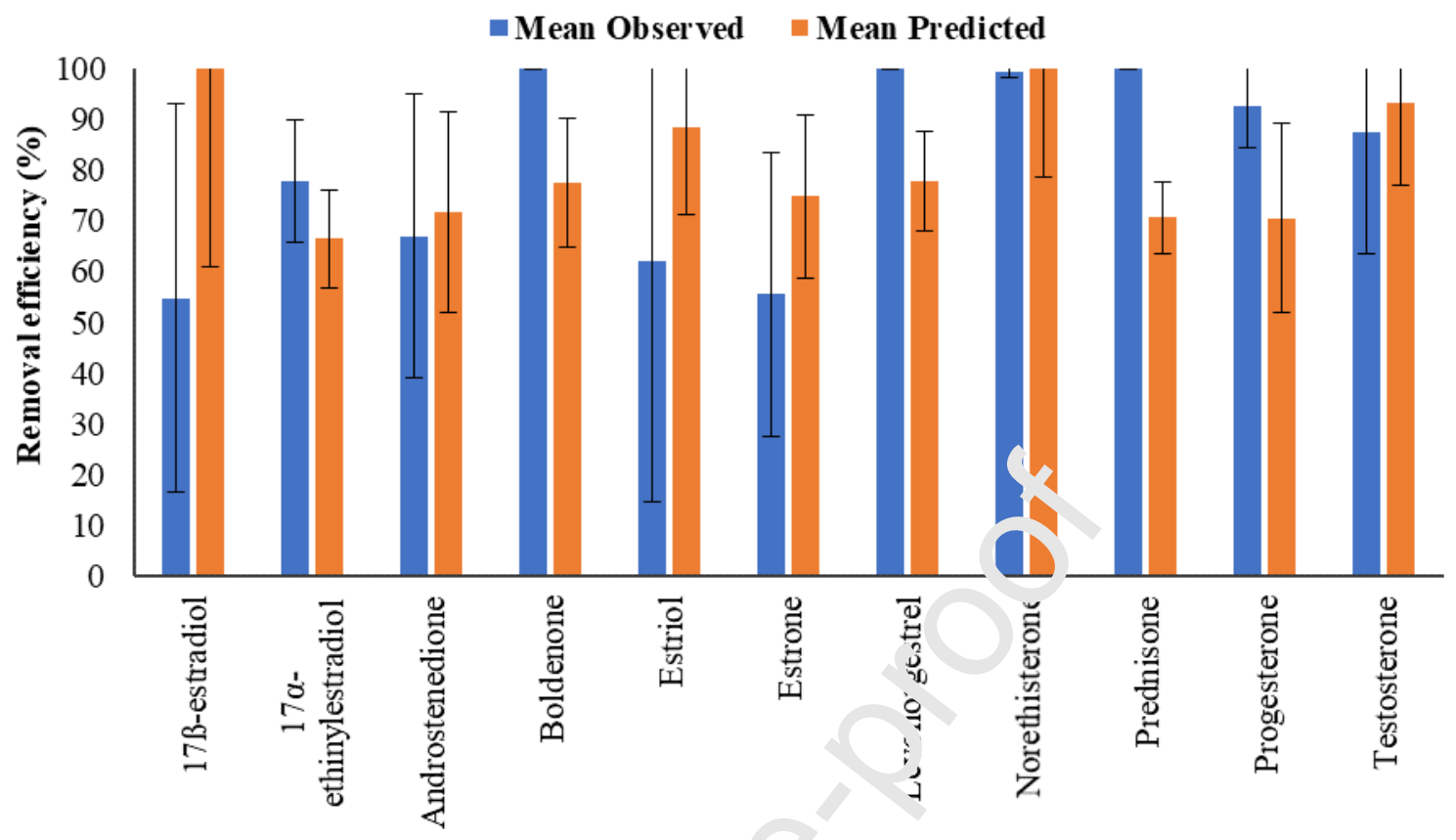

Figure 5. The expected removal efficiency of 1 . $\mathrm{s}$. Is $\llcorner$ ased on observed and predicted results in HCW.

Note: Standard deviation values were capped at 100 ` improve the readability of the graph. Actual values can be found in DTFT-CW.

\subsection{Application of decisic n :ree framework tool with support of DTFT-CW and}

\section{literature}

A step by step demonst. tion of the proposed decision tree framework tool is provided in this section.

\subsubsection{Step 1: Analysis of wastewater}

Since the composition of wastewater and presence of EOCs is likely to differ in different contexts, it is important to first examine the wastewater to be treated by CWs. Here, the evidence from a few selected studies is described to provide an overview of types of EOCs that may be found in different case study locations. The analysis of actual wastewater treated by full-scale 
CWs showed the occurrence of wide range of EOCs in different studies (e.g., Breitholtz et al., 2012; Matamoros and Salvadó, 2012; Verlicchi et al., 2013; Chen et al., 2014, 2016, 2019; Vymazal et al., 2015, 2017; Choi et al., 2016; Matamoros et al., 2016, 2017; Dai et al., 2017; Vystavna et al., 2017; Yi et al., 2017; Petrie et al., 2018).

For example, Petrie et al. (2018) examined the presence of 54 EOCs (PhCs, PCPs, SHs, and industrial chemicals-ICs) in three HFCWs used to treat effluent from wastewater treatment plant (WWTP) in UK. Among the investigated EOCs, some were fr' na in all the studied HFCWs (acetaminophen, clarithromycin, diclofenac, estrone, ibuprof $n$, , aproxen, sulfamethoxazole, and triclosan). Vymazal et al. (2015) investigated the pr $\approx \sim^{\wedge}$ of six SHs (17ß-estradiol, 17 $\alpha-$ ethinylestradiol, estriol, estrone, progesterone, and te,, $0 s_{\llcorner}$rone) in three HFCWs used to treat rural wastewater in Czech Republic. All the sua 2 SHs were found in the influent of three HFCWs except 17a-ethinylestradiol and t tol in one of the studied HFCW. Vymazal et al. (2017) examined the occurrence of 31 ocer types of EOCs (PhCs and PCPs) in four HFCWs used to treat rural wastewater in $2: n$ Republic. Seven out of 31 EOCs were detected in all sampling campaigns in the ir fluınt samples (acetaminophen, caffeine, diclofenac, furosemide, hydrochlorothiazide, ibur ro 'n, and metoprolol) and seven were found in at least $75 \%$ of the samples (clarithromycin, $\xi$ abapentin, ketoprofen, tramadol, triclocarban, triclosan, and warfarin).

A further examination of the above-mentioned studies clearly showed the presence of wide range of EOCs in different case study locations. Although in the indicated studies the list of investigated EOCs was different, some of the EOCs were common in all the cases indicating that these EOCs are most widely used and detected across different locations. Another important observation is the use of HFCW systems in all these study sites, which may not be most suitable type of CW to treat a wide range of EOCs detected in the wastewater. This highlights the need of 
exploring the best suited type of $\mathrm{CW}$ in each context. Since composition of wastewater may change overtime with the change of people's needs of using certain types of drugs in a given area, it is recommended to periodically analyse wastewater for the occurrence of EOCs. The frequency of such an analysis could be determined by monitoring of drug sales in combination with wastewater analysis. A re-analysis of wastewater could be recommended annually or at least after a few years (e.g., 3-5 years). If the re-analysis results in a significantly different set of EOCs than those used in the design of CWs, an adaptation should iu considered. The new design could be selected following step 2-5 of the proposed decisior ${ }^{+r_{c}}$ : ' ramework. More changes in the existing design could be expected when only one typ of CW (e.g., FWSCW, VFCW or HFCW) is used for wastewater treatment compared wil. $\mathrm{HCW}$ because later is expected to be

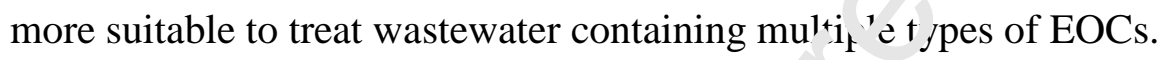

For the purpose of demonstration, 19 EOC (13 PhCs, one PCPs, and five SHs) were selected, which are included in the EU watch list 'EU, 2015, 2018; Barbosa et al., 2016; Gorito et al., 2017; Loos et al., 2018) and pos $\therefore 1$ : ol $_{11}$ environmental risk (Ilyas et al., 2020b, Ilyas and van

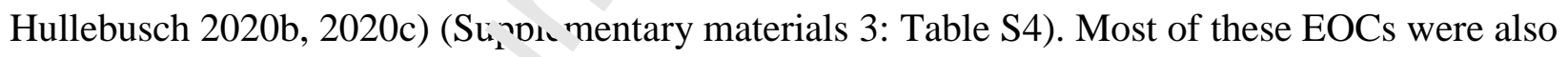
found in the wastewater a la! 'sed in the above-mentioned studies.

\subsubsection{Decision $~ n$ the list of EOCs}

For this demonstration we selected the 19 EOCs which are included in the EU watch list, and are classified under high environmental risk category.

\subsubsection{Step 2: Selection of CWs for each EOC}

The available evidence in the literature and physicochemical properties of EOCs indicate that specific processes are involved in the removal of a certain type of EOC in CWs (Ilyas and van 
Hullebusch, 2020a, 2020b, 2020c). In CWs various physical, chemical, and biological processes such as photodegradation, volatilization, adsorption/sorption, plant uptake and accumulation, and biodegradation (aerobic and anaerobic) may occur simultaneously; however, the dominance of removal mechanisms depends on the design of the CWs (e.g., Zhang et al., 2014; Gorito et al., 2017). For instance, in FWSCW, the major removal mechanism of EOCs is photodegradation, although biodegradation and plant uptake also contribute to the overall performance of the system. In HFCW and VFCW, due to the occurrence of anaerobı and aerobic conditions, the corresponding anaerobic and aerobic biodegradation contribrto the removal of EOCs besides their removal by the filter media (through sedimentation, a'sorption, and precipitation) and plant uptake. Due to the variation in the dominant removal 1 chanisms of different types of EOCs (Supplementary materials 5: TableS5), their remo 11 fficiency varies in different types of CWs (Figure 6).

For example, some of the selected $\mathrm{Ph} \Gamma_{\mathrm{s}}$ (- -etaminophen, oxytetracycline, and sulfadiazine) and PCPs (triclosan) showed better en. vval efficiency in FWSCW. The removal efficiency of triclosan was significantly hig.er : 7 FWSCW (97\%) compared with VFCW (88\%), HCW (77\%), and HFCW (59\%) (Figu $乞$. Although adsorption and/or sorption is one of its major removal mechanisms (Table S5, but its higher removal efficiency in FWSCW suggests that photodegradation might be a considerable removal pathway as well (Table S5). Few studies observed triclosan's high removal efficiency by photodegradation in hydroponic microcosm (69 $\pm 16 \%$ ) (Matamoros et al., 2012; Li et al., 2017). Its uptake by the plants cannot be considered in CWs due to its physicochemical properties (Ilyas and van Hullebusch, 2020b) but the indirect positive effects of plants presence such as biodegradation contributed to its removal. Its major removal process in CWs is aerobic biodegradation; however, some studies also attributed its 
removal to anaerobic biodegradation (Table S5). VFCW are predominantly aerobic compared with anoxic HFCW. Although it is easily biodegradable compound, the significantly higher removal efficiency in VFCW compared with HFCW (Ilyas and van Hullebusch, 2020b) can be explained by the fact that the aerobic biodegradation mainly contributes to its microbial degradation process. The comparatively better removal efficiency in HCW than HFCW might be due to the establishment of aerobic and anaerobic conditions.

On the other hand, the better removal efficiency of ofloxacin, $1 /$ ? -estradiol, and estrone in HFCW indicate the suitability of this type of $\mathrm{CW}$ for the rea ment of wastewater containing these EOCs. For instance, the removal of 17ß-estradio -as higher in HFCW (79\%) compared with $\mathrm{HCW}(55 \%), \mathrm{VFCW}(54 \%)$, and FWSCW (53\%) ( $\mathrm{F}_{2}$ vure 6), although exhibits statistically significant difference only with FWSCW (Ilv' ts $\ldots$ d van Hullebusch, 2020c). Some studies

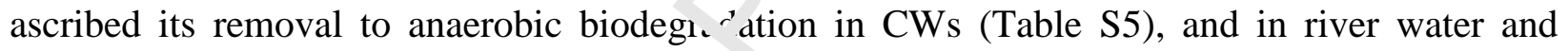
anaerobic sediments (Jürgens et al., 2n(L) which is evident by its better removal in HFCW-

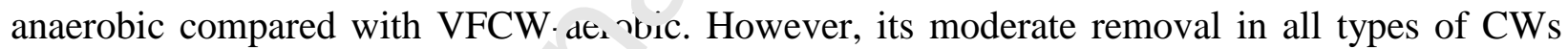
might be due to the other m:io processes responsible for its removal such as sorption onto organic surfaces, biotrans Or naton into estrone, plant uptake, and photodegradation (Table S5).

In further contrast, the $\mathrm{V}_{\mathcal{F}} \mathrm{CW}$ showed better performance for the removal of clarithromycin, ibuprofen, naproxen, salicylic acid, estriol, and testosterone, which is coherent with the dominant removal mechanism (aerobic biodegradation) of these PhCs and SHs in CWs (Table S5). For instance, the removal efficiency of ibuprofen with VFCW was much higher (79\%) compared with $\mathrm{HCW}(62 \%)$, FWSCW (57\%), and HFCW (53\%) (Figure 6). However, its removal efficiency exhibits significant differences only in the case of FWSCW and HFCW (Ilyas and van Hullebusch, 2020a). It is easily biodegradable compound (Hijosa-Valsero et al., 2011) and its 
major removal process in CWs is aerobic biodegradation. The higher removal efficiency in VFCW-aerobic compared with HFCW-anoxic can be explained by the fact that the aerobic biodegradation mainly contributes to its microbial degradation process (Table S5). However, the moderate removal in all types of CWs indicate the contribution of other removal pathways such as plant uptake, adsorption, and photodegradation (Table S5). Photodegradation may take place only in unplanted free water surface (FWS) on top of horizontal flow filter (HFF) (ReyesContreras et al., 2012). 


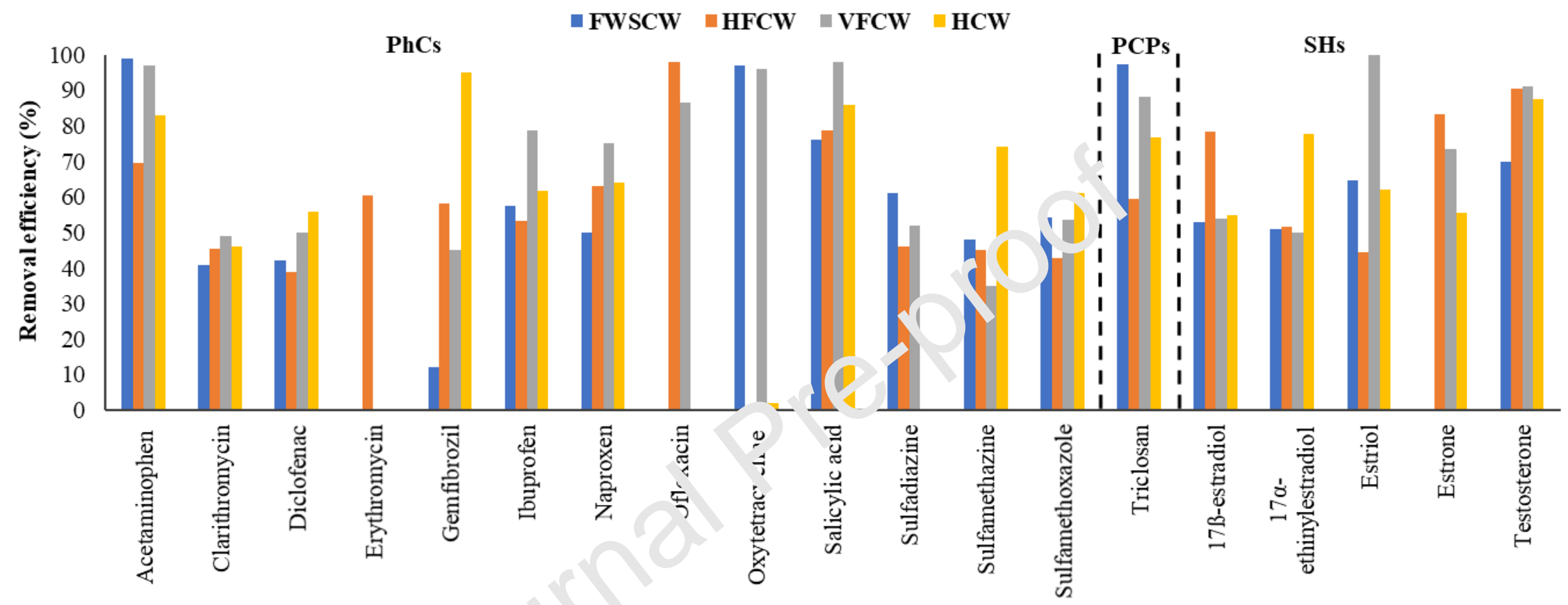

Figure 6. The observed removal efficiency of 1: EC Is in four types of CWs. 
Finally, the HCW performed best for the removal of diclofenac, erythromycin, gemfibrozil, sulfamethazine, sulfamethoxazole, and 17 $\alpha$-ethinylestradiol. For instance, the removal efficiency of diclofenac was better in HCW (56\%) compared with VFCW (50\%), FWSCW (42\%), and HFCW (39\%) (Figure 6), although shows statistical differences only with HFCW (Ilyas and van Hullebusch, 2020a). Its lower to moderate removal efficiency might be due to the presence of chlorine in its structure, which makes it highly recalcitrant to biodegradation (Kimura et al., 2005). Some studies suggested that high redox potential in CWs wirld promote its removal by aerobic biodegradation (Table S5). In contrast, it has alsr $h_{t}=$ suggested that its removal efficiency could be enhanced under anaerobic conditions 'biodegradation) (Table S5). Several studies attributed the higher removal of diclofenac in $40 v$ compared with HFCW and VFCW due to the coexistence of aerobic and anaerobic c ad ions in HCW (e.g., Hijosa-Valsero et al., 2010; Ávila et al., 2014; Kahl et al., 2017, Ni ala et al., 2019). For instance, Nivala et al. (2019) reported that the removal of diclofenac $\mathrm{HCW}$, VFCW, and HFCW was $77 \%, 53 \%$, and $25 \%$, respectively. In FWSCW, it is mair'v ${ }^{1}{ }^{\circ}$ oved by photodegradation (Table S5). Its high removal by photodegradation was achit ed in hydroponic microcosm (79 $\pm 2 \%$ ) (Zhang et al., 2012, 2013), and it was confirmer $b_{j} ;$ s higher removal in the unplanted HCW system (FWS on top of the HFF) (29\%) durit ${ }_{i}$ summer which provides the most appropriate environment for photodegradation compared with planted HCW (1.7\%) (Reyes-Contreras et al., 2012)

\subsubsection{Decision on the suitable type of CWs for the given list of EOCs}

The decision on the suitable type of CWs can be made based on the performance of CWs for the removal efficiency of selected EOCs. The available scientific evidence in the literature indicated that FWSCW is the most suitable type of $\mathrm{CW}$ for the treatment of wastewater containing acetaminophen, oxytetracycline, sulfadiazine, and triclosan. The HFCW performed better for the 
removal of ofloxacin, 17ß-estradiol, and estrone, and VFCW showed comparatively better removal efficiency of clarithromycin, ibuprofen, naproxen, salicylic acid, estriol, and testosterone. However, HCW is the best for the removal of diclofenac, erythromycin, gemfibrozil, sulfamethazine, sulfamethoxazole, and 17 $\alpha$-ethinylestradiol. These results indicate that there is no single $\mathrm{CW}$ most suitable to treat the list of EOCs under consideration.

\subsubsection{Step 3: Selection of CWs based on selected EOCs}

In the case of selected EOCs, HCW and VFCW showed better pe, formance for the removal of six out of 19 EOCs (Supplementary materials 4: Figure S2, Th 2 one option could be to select either HCW or VFCW for the treatment of wastewater con taning these EOCs, although HFCW and FWSCW are the best type of CWs for the remavd of inree and four out of 19 EOCs under consideration, respectively.

The other option is to consider integrated desion to ensure the contribution of different removal mechanisms to the removal of these $\mathrm{E}^{\prime} \mathrm{J}^{\mathrm{s}} \mathrm{s}$ in $\mathrm{CWs}$ as mentioned in the previous step. Several studies indicated the need of int $\mathrm{g}_{1}{ }^{\text {}}$ ted design of $\mathrm{HCW}$ that should contain features of different types of CWs. For instance, the 1 . quired aerobic and anaerobic environments to achieve efficient removal of EOCs nec 's1 ^te combining VFCW with HFCW (Hijosa-Valsero et al., 2010; Ávila et al., 2014; Kahl et al., ¿u17; Nivala et al., 2019) to achieve reductive and oxidative processes in CWs (e.g., Armenante et al., 1992; Master et al., 2002; Vymazal, 2005). On the other hand, the other types of HCWs such as FWSCW combined with VFCW and/or HFCW are also known to enhance the performance of CWs for the removal of conventional parameters (Vymazal, 2013). Consistent with that the integrated design of CWs by combining all the three types of CWs: VFCW, HFCW, and FWSCW can enhance the performance of the system for the removal of multiple types of EOCs. 


\subsubsection{Decision on final type of CW system}

An integrated design of HCW by combining VFCW, HFCW, and FWSCW is recommended as the best option for the removal of 19 selected EOCs.

\subsubsection{Step 4: Design and operational parameters of the recommended CW}

The DTFT-CW did calculations of the design and operational parameters of four types of CWs for the removal of selected 19 EOCs, which are given in Table 2. The focus in this section is to investigate suitable design and operation parameters of $\mathrm{HCW}$ t lat /as selected as the best $\mathrm{CW}$ type for the EOCs under consideration. The mean and stcan ard deviation of area, depth, HLR, HRT, and OLR, and best-count in the case of plants $a \cdot d$ st pport matrix provide initial range of values for engineering design of the proposed $\mathrm{H} \cdots \mathrm{V}$ (Table 2). Further insights are discussed here based on a few studies involving $\mathrm{H} r \mathrm{n}$ tie investigated HCWs were a combination of different types of conventional CWs such as VFCW + HFCW, HFCW + VFCW, VFCW + VFCW, HFCW + HFCW, HCW incl Idn; FWSCW, and also multistage of more than two types of CWs (Ilyas et al., 2020b; Ilya; a.d van Hullebusch, 2020a, 2020b, 2020c). Only a few studies considered the integrated design of CWs by combining all the three types of CWs (FWSCW, HFCW, and VFCW) (1' ${ }^{1}{ }^{1} \neg f_{i}$ al., 2014, 2015; Vystavna et al., 2017; Sgroi et al., 2018), which are discussed in detail hıe.

Ávila et al. (2014) investigated the performance of a pilot-scale HCW (two parallel VFCWs alternating their operation followed by HFCW and FWSCW operating in series) in Spain to treat primary effluent. The wastewater was spiked with different categories of EOCs (PhCs, PCPs, SHs, and ICs). The PhCs, PCPs, and SHs were 17 $\alpha$-ethinylestradiol, acetaminophen, diclofenac, ibuprofen, oxybenzone, tonalide, and triclosan. The removal efficiency of $\mathrm{PhCs}$ (acetaminophen, diclofenac, and ibuprofen) was high (80\% to $100 \%)$ at three HLRs $\left(0.06,0.13\right.$, and $0.18 \mathrm{~m}^{3} \mathrm{~m}^{-2} \mathrm{~d}^{-}$ 
${ }^{1}$ ) and OLRs (37, 110, and $\left.159 \mathrm{~g} \mathrm{COD} \mathrm{m}^{-2} \mathrm{~d}^{-1}\right)$ with corresponding HRTs (4.0, 2.0, and 1.5 days). The area required per population equivalent $(\mathrm{PE})$ for three configurations was $2.7,0.9$, and 0.6 $\mathrm{m}^{2} \mathrm{PE}^{-1}$, respectively. However, the removal efficiency decreased with increasing HLR and OLR, and decreasing HRT and area requirements. Similarly, the removal efficiency of PCPs (oxybenzone, tonalide, and triclosan) was high (85\% to 96\%) at three HLRs, OLRs, HRTs, and areas. Nevertheless, the removal efficiency decreased with increasing HLR and OLR, and decreasing HRT and area. The corresponding removal efficiency \& $17 \alpha$-ethinylestradiol (SHs) was $76 \%, 73 \%$, and $67 \%$, respectively, which also indicated the nilar pattern at three HLRs, OLRs, HRTs, and areas. 
Table 2. Design and operational parameter values derived from available scientific evidence related to the selected 19 EOCs.

\begin{tabular}{|c|c|c|c|c|c|c|c|}
\hline CW type & $\begin{array}{c}\begin{array}{c}\text { Depth } \\
(\mathbf{m})\end{array} \\
\text { Mean } \pm \text { Stdev } \\
\end{array}$ & $\begin{array}{c}\text { Area } \\
\left(\mathbf{m}^{2} \mathbf{P E}^{-1}\right) \\
\text { Mean } \pm \text { Stdev }\end{array}$ & $\begin{array}{c}\text { HLR } \\
\left(\mathrm{m}^{3} \mathbf{m}^{-2} \mathbf{d}^{-1}\right) \\
\text { Mean } \pm \text { Stdev } \\
\end{array}$ & $\begin{array}{c}\text { OLR } \\
\left(\text { g COD m}^{-2} d^{-1}\right) \\
\text { Mean } \pm \text { Stdev }\end{array}$ & $\begin{array}{c}\text { HRT } \\
\text { (days) } \\
\text { Mean } \pm \text { Stdev } \\
\end{array}$ & $\begin{array}{c}\text { Plant } \\
\text { Based on Best-Count }\end{array}$ & $\begin{array}{c}\text { Support matrix } \\
\text { Based on Best-Count }\end{array}$ \\
\hline FWSCW & $0.61 \pm 0.24$ & $10.29 \pm 7.33$ & $0.12 \pm 0.09$ & $23.66 \pm 21.32$ & $4.76 \pm 1.78$ & Typha angustifolia & Gravel \\
\hline HFCW & $0.68 \pm 0.14$ & $6.75 \pm 2.03$ & $0.48 \pm 0.58$ & $18.25 \pm 9.96$ & $5.52 \pm 3.12$ & Phragmites australis & Gravel \\
\hline VFCW & $0.60 \pm 0.11$ & $5.88 \pm 4.56$ & $0.14 \pm 0.07$ & $29.66 \pm 16.15$ & $2.19 \pm 2.07$ & Phragmites australis & Sand \\
\hline $\mathrm{HCW}$ & $1.09 \pm 0.30$ & $6.43 \pm 3.83$ & $0.24 \pm 0.20$ & $84.54 \pm 95.36$ & $5.59 \pm 2.62$ & 'hragmites australis & Gravel \\
\hline
\end{tabular}


A full-scale HCW by combining two VFCWs followed by HFCW and FWSCW operating in series was examined by Vystavna et al. (2017) for the secondary treatment of hospital wastewater in Ukraine. The different categories of 12 EOCs (PhCs, PCPs, and SHs) were found in primary treated wastewater, which were acetaminophen, androstenedione, caffeine, carbamazepine, diclofenac, estrone, ibuprofen, ketoprofen, naproxen, propranolol, triclosan, and venlafaxine. The removal efficiency of $\mathrm{PhCs}$ (acetaminophen, caffeine, carbamazepine, diclofenac, ibuprofen, ketoprofen, naproxen, propranolol, and venia $\left.{ }^{c}{ }^{9} \mathrm{xine}\right)$ was low to moderate $(<25 \%$ to $>50 \%)$ at two HLRs $\left(0.02\right.$ and $\left.0.03 \mathrm{~m}^{3} \mathrm{~m}^{-2} \mathrm{~d}^{-1}\right)$ and $\bigcap_{\mathrm{L}} \mathrm{n}$. $\left(2.1\right.$ and $\left.4.4 \mathrm{~g} \mathrm{COD} \mathrm{m}^{-2} \mathrm{~d}^{-1}\right)$ with corresponding HRTs (10 and 13 days). In contrast wı h the study by Ávila et al. (2014) the removal efficiency of PhCs increased with increasing $i: R$ and OLR. Similarly, the removal efficiency of triclosan (PCPs) was high (97\%) ' itt $^{\prime}$ increasing HLR, OLR, and HRT, and moderate $(50 \%)$ at low HLR, OLR, a.d JRT. The corresponding removal efficiency of androstenedione (SHs) was $45 \%$ and $5 \mathrm{\gamma} \%$ respectively, which also indicated the similar pattern at two HLRs, OLRs, and HRTs. Novert.leless, the removal efficiency of estrone (SHs) (43\%) was not affected with increasing HLK, OLR, and HRT.

Sgroi et al. (2018) inver ag، ${ }^{+}$eu the performance of a pilot-scale HCW (VFCW, HFCW, and FWSCW connected in ser es) in Spain to treat primary effluent. The PhCs and PCPs selected for treatment were caffeine, trimethoprim, sulfamethoxazole, N,N-diethyl-meta-toluamide, and sucralose. The removal efficiency of caffeine, trimethoprim, and sulfamethoxazole was $99 \%$, $100 \%$, and $74 \%$, respectively at HLR of $0.1 \mathrm{~m}^{3} \mathrm{~m}^{-2} \mathrm{~d}^{-1}$ and OLR of $40 \mathrm{~g} \mathrm{COD} \mathrm{m}^{-2} \mathrm{~d}^{-1}$. The depth of VFCW, HFCW, and FWSCW was $0.8,0.3$, and $0.5 \mathrm{~m}$, respectively and the area required per PE was $1.6 \mathrm{~m}^{2} \mathrm{PE}^{-1}$. The removal efficiency of N,N-diethyl-meta-toluamide $80 \%$. However, sucralose was not removed under these design and operational conditions. 
Ávila et al. (2015) explored the treatment performance of a full-scale HCW (VFCW, HFCW, and FWSCW connected in series) in Spain for the removal of EOCs (PhCs and PCPs) from primary treated combined sewer effluent (i.e., domestic wastewater together with the urban runoff). The PhCs and PCPs identified in wastewater were acetaminophen, diclofenac, ibuprofen, tonalide, and triclosan. The removal efficiency of acetaminophen, diclofenac, and ibuprofen was $99 \%, 86 \%$, and $>99 \%$, respectively at HLR of $0.04 \mathrm{~m}^{3} \mathrm{~m}^{-2} \mathrm{~d}^{-1}$, OLR of $11 \mathrm{~g} \mathrm{COD}$ $\mathrm{m}^{-2} \mathrm{~d}^{-1}$ with corresponding HRT of 7.4 days. The depth of VFC n HFCW, and FWSCW was $0.8,0.4$, and $0.3 \mathrm{~m}$, respectively and the area required per nt. $\cdots \mathrm{as} 11 \mathrm{~m}^{2} \mathrm{PE}^{-1}$. The removal efficiency of tonalide and triclosan was $94 \%$ and $77 \%$, espectively under these design and operational conditions.

Although the removal efficiency of most of the ituc: ${ }^{-1}$ EOCs was high in HCWs constructed by connecting VFCW, HFCW, and FWSC ${ }^{\prime}$, in series, the design and operational parameters showed a wide range of variation. Therel re, the users may select the final design according to their context and by considering n os. resevant scientific evidence based on the results of DTFTCW (Table 2) and most relevart $\mathrm{i}^{\star}$-rature.

In addition to the abcve- nen ioned design and operational parameters of CWs, suitable type of plants and a support matrix in CWs also play a pivotal role in enhancing the performance of the system for the removal of EOCs. Ilyas and van Hullebusch (2019, 2020c, 2020d) conducted a comprehensive and critical review of the performance and a comparison of all types of planted and unplanted CWs for the removal of PhCs, PCPs, and SHs based on available literature. The role of support matrix in the removal of these categories of EOCs by using the substrate material of high adsorption capacity, rich in organic/inorganic surfaces, and high surface area is also 
summarized in these studies. A brief description on the role of plants and a support matrix in the removal of EOCs is given here, and details can be found in the given literature.

In the case of PhCs, the removal efficiency of diclofenac, ibuprofen, naproxen, salicylic acid, caffeine, carbamazepine, gemfibrozil, and sulfamethoxazole was higher in the planted CWs compared with unplanted CWs. Large variety of plants were used in different types of CWs for the removal of PhCs. For instance, Cyperus alternifolius, Phragmites australis, Salix alba, Scirpus Validus, Spirodela polyrhiza, Thalia dealbata, Typha ar^usifolia, and Typha latifolia. Nevertheless, the most commonly used plants were Phragmi es . 'ustralis and Typha angustifolia (Ilyas and van Hullebusch, 2019). In the case of PCPs, th vinnted CWs performed better for the removal efficiency of galaxolide, methyl dihydrojas . $_{\text {. }}{ }^{+}$e, tonalide, and triclosan compared with unplanted CWs. Different types of plants tre $\cdots$ ed in all types of CWs for the removal of PCPs depending upon the availability or lants in different climatic regions. For example, Landoltia punctate, Lemna minor, Phrag, rites australis, Spirodela polyrhiza, Thalia dealbata, Typha angustifolia, and Typha lat fo: $\because$. However, the most widely used plants were Phragmites australis and Typha angustifc ${ }^{1}$ ia 'Tlyas and van Hullebusch, 2020d). In the case of SHs, 17aethinylestradiol showed siz nilicantly higher (almost twice) removal efficiency in planted compared with unplanted IWs. Among the plants used in different types of CWs for the removal of SHs were Cyperus isocladus, Juncus effuses, Myriophyllum, Phragmites australis, and Typha latifolia. However, Cyperus isocladus and Eichhornia crassipes were used in planted CWs while comparing their performance with unplanted CWs (Ilyas and van Hullebusch, 2020c).

Next to the plants, in CWs adsorption to the substrate and/or sorption onto organic/inorganic surfaces is one of the major removal mechanisms that could contribute to eliminating $\mathrm{PhCs}$, PCPs, and SHs from wastewater. The performance of different types of CWs for the removal of 
PhCs was examined by using substrate material of high adsorption capacity, rich in organic/inorganic surfaces, and high surface area such as sand, gravel (volcanic/river), light expanded clay aggregates (LECA), oyster shell, zeolite, medical stone, ceramic, brick particlebased media, vesuvianite (natural porous medium), and soil organic matter (SOM). The performance of CWs for the removal of PhCs was enhanced by using several of these substrates (Ilyas and van Hullebusch, 2019).

The performance of CWs for the removal of PCPs was improved $b_{j}$ using different substrates

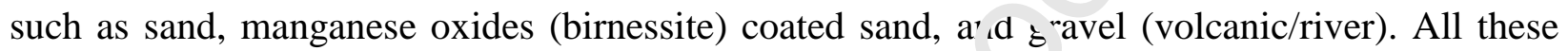
substrates improved the removal efficiency of PCPs in Fivs (Ilyas and van Hullebusch, 2020d). Similarly, several substrate media were tested to enhar ${ }^{2}$ ce the removal efficiency of SHs in CWs such as palm mulch-organic substrate media, gr.ıve;, 'apilli, and bamboo charcoal (Ilyas and van Hullebusch, 2020c).

\subsubsection{Decision on values of ie : in and operational parameters}

Integrated design of $\mathrm{HCW}$ ty combining VFCW, HFCW, and FWSCW in series is recommended for the remsval of multiple types of EOCs (PhCs, PCPs, and SHs) from wastewater. The reco $\urcorner m_{1} \cdot n d \dot{d}$ values of design and operational parameters are based on the available scientific eviaunce. The range of values for operational parameters could be: HLR: $0.24 \pm 0.20 \mathrm{~m}^{3} \mathrm{~m}^{-2} \mathrm{~d}^{-1} ;$ OLR: $84.54 \pm 95.36 \mathrm{~g} \mathrm{COD} \mathrm{m}^{-2} \mathrm{~d}^{-1}$; and HRT: $5.59 \pm 2.62$ days. The overall depth of HCW could be $1.09 \pm 0.30 \mathrm{~m}$, while the depths of VFCW, HFCW, and FWSCW could be $0.7,0.4$, and $0.3 \mathrm{~m}$, respectively. The area required per PE can be in the range of $6.43 \pm$ $3.83 \mathrm{~m}^{2} \mathrm{PE}^{-1}$. We propose to distribute the area among the three types of CWs according to a weighting factor estimated based on the number of EOCs for which each type of CW was best suited. For example, in the case of selected 19 EOCs, the highest weight was given to VFCW 
followed by FWSCW and HFCW (Figure S2). The weights for VFCW, HFCW, and FWSCW were estimated as $0.46,0.23$, and 0.31 ; hence, the proposed area of each unit was estimated as 3.0, 1.5, and $2.0 \mathrm{~m}^{2} \mathrm{PE}^{-1}$.

Based on available scientific evidence as mentioned-above different types of plants can be used in all types of CWs for the removal of these types of EOCs depending upon the availability of plants in different climatic regions. Nevertheless, in addition to the use of most investigated plants such as Phragmites australis and Typha angustifolia primity -hould be given to use the plants which were at least considered in few studies sura a Cyperus alternifolius, Thalia dealbata, and Typha latifolia.

Similarly, as indicated above several types of substantes materials (high adsorption capacity, rich in organic/inorganic surfaces, and high surf ^e, a"ea) can be used as a support matrix in different types of CWs to enhance the removal effic ncy of EOCs. However, in addition to the use of sand and gravel (volcanic/river), the $\mathrm{u}_{\mathrm{N}} \mathrm{or}$ any of the investigated substrate materials such as LECA, zeolite, brick particle-ba ${ }^{2}$ hedia, vesuvianite, SOM, manganese oxides (birnessite) coated sand, palm mulch-organi- substrate media, lapilli, and bamboo charcoal can be beneficial to improve the performar se oWs.

\subsubsection{Step 5: Comparison of observed and predicted removal efficiency of EOCs}

The DTFT-CW readily provides the estimates on observed and predicted removal efficiencies of the selected 19 EOCs. The results are available in Tabular and Graphical form for the review of the users. For example, Figure 7 displays the mean and standard deviation of the observed and predicted removal efficiency of the selected 19 EOCs in case of HCWs. The observed values are based on the synthesis of the experimental studies, while predicated efficiencies are calculated 
using multiple linear regression models of removal efficiency based on physicochemical properties of the EOCs, and design and operational parameters of the CWs.

The results show reasonably good removal efficiency for most of the EOCs, as 15 out 19 EOCs indicated removal efficiency of above $50 \%$ on average. Testosterone indicated highest removal, while erythromycin depicted lowest removal efficiency. However, in general, the performance of the proposed CW system could be considered acceptable in most cases.

Moreover, the users are advised to consider uncertainties aris ng from experimental data and prediction modelling process. For example, the analysis eve $\mathrm{ls}$ that there is a quite large uncertainty range shown by high standard deviation in cas ' of observed removal efficiencies of half of the selected 19 EOCs (Figure 7). This jr-dicates considerable differences in removal efficiencies under different environmental $n_{\mathrm{L}}$ operational conditions of CWs (Ilyas et al., 2020a). The performance of HCWs is no investigated by the experimental studies for the removal of erythromycin, ofloxacin, ill suifadiazine. Therefore, the comparison of the observed removal efficiency of these $\mathrm{PhC}$ is sot possible with the predicted removal efficiency. The predictions of the removal eificiency of ofloxacin and sulfadiazine in HCW indicate the moderate removal of the e $\mathrm{P}$ Cs form the wastewater $(79 \pm 22 \%$ and $61 \pm 10 \%$, respectively). However, the predicter emoval efficiency of erythromycin was low $(25 \pm 4 \%)$ in $\mathrm{HCW}$. Nevertheless, in most cases where the comparison was possible, the mean of predicted removal efficiency is in close agreement with the observed values, as it falls well within the range of standard deviation in most cases (Figure 7). The observed removal efficiency of oxytetracycline is very low in $\mathrm{HCW}(2.0 \%)$ and the predicted removal efficiency shows its moderate to high removal in $\mathrm{HCW}(71 \pm 32 \%)$. In contrast the observed removal efficiency of gemfibrozil is very 
high in $\mathrm{HCW}(95 \%)$ and the predicted removal efficiency shows its low to moderate removal in HCW $(37 \pm 12 \%)$. However, in both cases the number of observed data points is only one.

Nevertheless, the predictions made by various regression models is not much different from each other, as indicated by small standard deviation of the predicted values $(<10 \%$ in most cases). Therefore, the removal efficiencies can be predicted with reasonably good accuracy by using the proposed individual models or by estimating mean and standard deviations based on all plausible

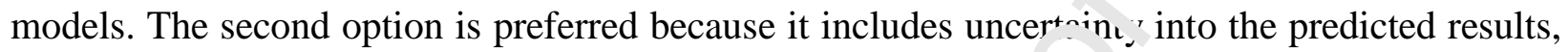
and hence include uncertainty in the decision-making procers. I.owever, the predicated removal efficiencies should be interpreted with caution. These $\mathrm{p}^{\text {redic }}$ : ions could not be taken as absolute numbers; neither these should be considered as a subs ${ }^{\star}$ tul for rigorous experimental studies for a given context.

\subsubsection{Decision on performance}

The performance of the recommend $\cdot d r^{2} \mathrm{ZW}$ is acceptable for the removal of the selected 19 EOCs, which are classified unde : 1. on environmental risk category and included in the EU watch list. 


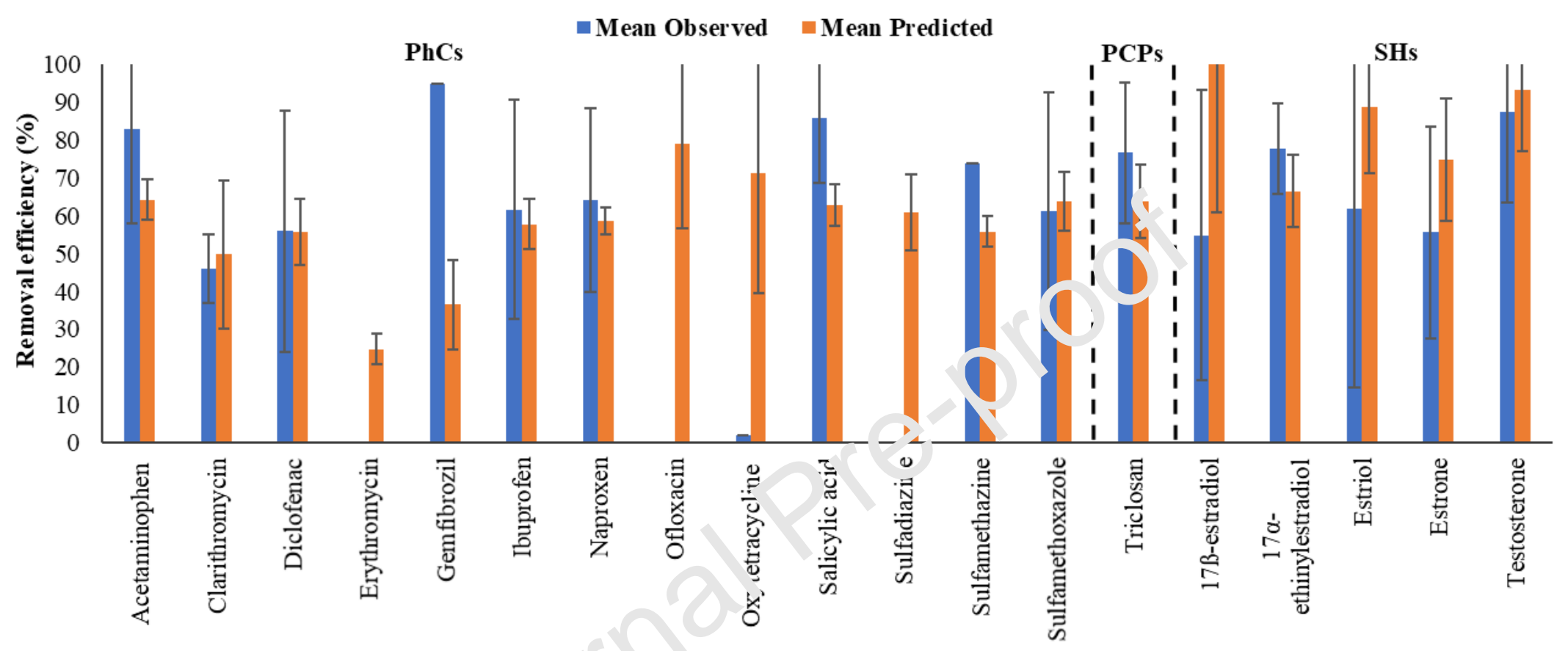

Figure 7. The expected removal efficiency of $19 t x$ : based on observed and predicted results in HCW.

Note: Standard deviation values were capp. I a $10 \mathrm{C}$ to improve the readability of the graph. Actual values can be found in DTFT-CW. 


\section{Conclusions}

CWs have been extensively investigated for the treatment of wastewater containing different categories of EOCs. However, the research is lacking on developing tools for supporting decision making process on the design and operation of CWs and associated performance for the removal of EOCs. In this study, we developed and applied two novel tools to aid decision making process: first, a novel decision tree framework, and seconc a data and information-based tool to support the application of decision tree framework.

The following specific conclusions are drawn from this wor'r

1. The proposed decision tree framework demonstr tes :igh potential to improve knowledge and support applications for the remov 1 o EOCs by different types of CWs. The comprehensive coverage on various $\mathrm{a}_{2}$ ects of $\mathrm{CW}$ design, operation, and performance is supported by best available scientili evidence. The tool could be useful for multiple decision makers such as poli. $\mathrm{y}_{\llcorner}$'akers, design engineers and operators, research scientists, educationists, and citizen

2. A novel data and in on ation tool (named as DTFT-CW) readily provides sound scientific information and data to support the application of the proposed decision tree framework. The current version is able to provide data and information for 59 EOCs ( $33 \mathrm{PhCs}, 15 \mathrm{PCPs}$, and $11 \mathrm{SHs})$.

3. The proposed tools are applicable in various context as demonstrated in the case of 19 EOCs (13 PhCs, one PCPs, and five SHs), which pose high environmental risk including six EOCs that are included in the EU watch list. This application provides a useful guide for the decision makers to use the proposed tools in any given context. 
4. An integrated design of $\mathrm{HCW}$ by combining VFCW, HFCW, and FWSCW in series is recommended for the removal of multiple types of EOCs (PhCs, PCPs, and SHs) from wastewater. Thus, most widely used $\operatorname{HFCW}(\mathrm{s})$ (either alone or in combination) could be redesigned and replaced with integrated systems when multiple types of EOCs needs to be treated.

5. The decision tree framework tool provides preliminary information on several design and operational parameters as well as the expected performance $o_{\Perp}$, nost suitable CW system for any sub-set of the 59 examined EOCs. For example, for the 1 - ommended HCW to treat 19 selected EOCs, preliminary values of design and opera ional parameters are suggested based on the available scientific evidence. The range of v iues for operational parameters could be: HLR: $0.24 \pm 0.20 \mathrm{~m}^{3} \mathrm{~m}^{-2} \mathrm{~d}^{-1}$; OLR: $84.54 \div 9 ; .36 \mathrm{~g} \mathrm{COD} \mathrm{m}^{-2} \mathrm{~d}^{-1}$; and HRT: $5.59 \pm 2.62$ days. The overall depth of HCW c. 'll be $1.09 \pm 0.30 \mathrm{~m}$, while the depths of VFCW, HFCW, and FWSCW could be $0 . \%, 9.4$, and $0.3 \mathrm{~m}$, respectively. The area required per PE can be in the range of $6.43 \pm 283 \mathrm{~m} \mathrm{PE}^{-1}$. Different types of plants can be used in all types of CWs for the removal of . hese types of EOCs depending upon the availability of plants in different climatic reginns. Jevertheless, priority should be given to the most investigated plants proven to in. rove the performance of CWs such as Phragmites australis, Typha angustifolia, Cyperus alternifolius, Thalia dealbata, and Typha latifolia. Similarly, several types of substrates materials with high adsorption capacity, rich in organic/inorganic surfaces, and high surface area can be used in different types of CWs to enhance the removal efficiency of EOCs. Therefore, in addition to the use of sand and gravel (volcanic/river), the use of any of the investigated substrate materials such as LECA, zeolite, brick particle-based media, vesuvianite, SOM, manganese oxides (birnessite) coated sand, 
palm mulch-organic substrate media, lapilli, and bamboo charcoal can be beneficial to improve the performance of CWs.

6. The proposed tools could be further enhanced in the future by including more EOCs, reducing uncertainty in the used data sets, and including more areas of interests for the decision makers.

\section{References}

Armenante, P.M., Kafkewitz, D., Lewandowski, G., Kung, C.M, 1ะñ. Integrated anaerobic-aerobic process for the biodegradation of chlorinated aromatic ompounds. Environmental Progress \& Sustainable Energy. 11, 113-122.

Ávila, C., Bayona, J.M., Martín, I., Salas, J.J., García, 1.. 2C15. Emerging organic contaminant removal in a full-scale hybrid constructed wetland sy ten. for wastewater treatment and reuse. Ecological Engineering. 80, 108-116.

Ávila, C., Matamoros, V., Reyes-Contr ra ,, C., Piña, B., Casado, M., Mita, L. Rivetti, C., Barata, C., García, J., Bayona, J.M., 20ะ1. A.tenuation of emerging contaminants in a hybrid constructed wetland system under diffe. ${ }^{\prime} \mathrm{n}$ ' hydraulic loading rates and their associated toxicological effects in wastewater. Science ( / th. Total Environment. 470-471, 1272-1280.

Barbosa, M.O., Moreira, N. F.F., Ribeiro, A.R., Pereira, M.F.R., Silva, A.M.T., 2016. Occurrence and removal of organic micropollutants: An overview of the watch list of EU Decision 2015/495. Water Research. 94, 257-279.

Breitholtz, M., Näslund, M., Stråe, D., Borg, H., Grabic, R., Fick, J., 2012. An evaluation of free water surface wetlands as tertiary sewage water treatment of micro-pollutants. Ecotoxicology and Environmental Safety. 78, 63-71. 
Carvalho, P.N., Basto, M.C.P., Almeida, C.M.R., Brix, H., 2014. A review of plant-pharmaceutical interactions: from uptake and effects in crop plants to phytoremediation in constructed wetlands. Environmental Science and Pollution Research. 21 (20), 11729-11763.

Chen, J., Liu, Y-S., Deng, W-J., Ying, G-G., 2019. Removal of steroid hormones and biocides from rural wastewater by an integrated constructed wetland. Science of the Total Environment. 660, 358-365.

Chen, T-C., Yeh, K-J.C., Kuo, W-C., Chao, H-R., Sheu, S-C., 2014. Estrogen degradation and sorption onto colloids in a constructed wetland with different hydra'lic retention times. Journal of Hazardous Materials. 277, 62-68.

Chen, Y., Vymazal, J., Březinová, T., Koželuh, M., Kule, L., F uan. , J., Chen, Z., 2016. Occurrence, removal and environmental risk assessment of pharmar : 'tı als and personal care products in rural wastewater treatment wetlands. Science of the Total F $\iota v ı$, >nment. 566-567, 1660-1669.

Choi, Y-J., Kim, L-H., Zoh, K-D., 2016. Removal c. ıre teristics and mechanism of antibiotics using constructed wetlands. Ecological Engir ori, g. 91, 85-92.

Dai, Y., Tao, R., Tai, Y., Tam, N.F., L.n, A., Yang, Y., 2017. Application of a full-scale newly developed stacked constructed wetia id and an assembled bio-filter for reducing phenolic endocrine disrupting chemicals from se on' 'rry effluent. Ecological Engineering. 99, 496-503.

Ekperusi, A.O., Sikoki, F.D., I'wac ‘akwu, E.O., 2019. Application of common duckweed (Lemna minor) in phytoremediat; $\urcorner$, $f$ ch 2 micals in the environment: State and future perspective. Chemosphere. 223, 285-309.

European Union (EU), 2015. Commission Implementing Decision (EU) 2015/495 of 20 March 2015 establishing a watch list of substances for Union-wide monitoring in the field of water policy pursuant to Directive 2008/105/EC of the European Parliament and of the Council (OJ L 348, 24.12.2008, p. 84).

European Union (EU), 2018. Commission Implementing Decision (EU) 2018/840 of 5 June 2018 establishing a watch list of substances for Union-wide monitoring in the field of water policy 
pursuant to Directive 2008/105/EC of the European Parliament and of the Council (OJ L 348, 24.12.2008, p. 84), and repealing Commission Implementing Decision (EU) 2015/495.

Gorito, A.M., Ribeiro, A.R., Almeida, C.M.R., Silva, A.M.T., 2017. A review on the application of constructed wetlands for the removal of priority substances and contaminants of emerging concern listed in recently launched EU legislation. Environmental Pollution. 227, 428-443.

Hijosa-Valsero, M., Matamoros, V., Martin-Villacorta, J., Becares, E., Bayona, J.M., 2010. Assessment of full-scale natural systems for the removal of PPCPs from vastewater in small communities. Water Research. 44, 1429-1439.

Hijosa-Valsero, M., Sidrach-Cardona, R., Martín-Villacorta, J., Vaı ero-Blanco, M.C., Bayona, J.M., Bécares, E., 2011. Statistical modelling of organic $r_{-}+t_{.}$and emerging pollutants removal in constructed wetlands. Bioresource Technology. 102, 478, 4988.

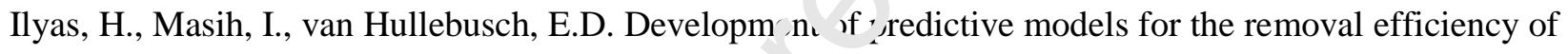
emerging organic contaminants in cons $\mathrm{uc}^{+}$d $\mathrm{d}$ wetlands based on their physicochemical properties. Journal of Environmental Manageme. ${ }^{`} \cdot$. (Under review)

Ilyas, H., Masih, I., van Hullebusch, L.J ., 2020a. Prediction of the removal efficiency of emerging organic contaminants based ( n c 'sign and operational parameters of constructed wetlands. Journal of Environmental Chemi $\curvearrowright$ al $\mathrm{t}$.gineering. (In press)

Ilyas, H., Masih, I., va. H. lleb isch, E.D., 2020b. Pharmaceuticals removal by constructed wetlands: a critical evaluation s m. meta-analysis on performance, risk reduction and role of physicochemical properties on removal mechanisms. Journal of Water and Health. 18 (3), 253-291.

Ilyas, H., van Hullebusch, E.D., 2019. Role of design and operational factors in the removal of pharmaceuticals by constructed wetlands. Water. 11 (11), 2356, 1-24.

Ilyas, H., van Hullebusch, E.D., 2020a. Performance comparison of different types of constructed wetlands for the removal of pharmaceuticals and their transformation products: a review. Environmental Science and Pollution Research. 27 (13), 14342-14364. 
Ilyas, H., van Hullebusch, E.D., 2020b. Performance comparison of different constructed wetlands designs for the removal of personal care products. International Journal of Environmental Research and Public Health. 17 (9), 3091, 1-26.

Ilyas, H., van Hullebusch, E.D., 2020c. A review on the occurrence, fate, and removal of steroidal hormones during treatment with different types of constructed wetlands. Journal of Environmental Chemical Engineering. 8 (3), 103793.

Ilyas, H., van Hullebusch, E.D., 2020d. The influence of design and opf rational factors on the removal of personal care products by constructed wetlands. Water. 12 (5), 1, jo, 1-20.

Jürgens, M.D., Holthaus, K.I.E., Johnson, A.C., Smith, J.J.L., He nerı 'ge, M., Williams, R.J., 2002. The potential for estradiol and ethinylestradiol degradation :... $\mathrm{F}_{1 .}$.lish rivers. Environmental Toxicology and Chemistry. 21, 480-488.

Kahl, S., Nivala, J., Afferden, M.V., Müller, R.A., Fec nts na, T., 2017. Effect of design and operational conditions on the performance of ' Ibs rfface flow treatment wetlands: Emerging organic contaminants as indicators. Water Re $e^{\prime}$ arch. 125, 490-500.

Kimura, K., Hara, H., Watanabe, Y., 2'ر0:. Removal of pharmaceutical compounds by submerged membrane bioreactors (MBR ;). ₹esalination. 178, 135-140.

Li, J., Zhou, Q., Campos, L.C, 2 17. Removal of selected emerging PPCP compounds using greater duckweed (Spiro' 'ola nol rhiza) based lab-scale free water constructed wetland. Water Research. $126,252-261$.

Li, Y., Zhu, G., Ng, W.J., Tan, S.K., 2014. A review on removing pharmaceutical contaminants from wastewater by constructed wetlands: Design, performance and mechanism. Science of the Total Environment. 468-469, 908-932.

Loos, R., Marinov, D., Sanseverino, I., Napierska, D., Lettieri, T., 2018. Review of the $1^{\text {st }}$ Watch List under the Water Framework Directive and recommendations for the $2^{\text {nd }}$ Watch List, EUR 29173 EN, Publications Office of the European Union, Luxembourg. 
Master, E.R., Lai, V.W.M., Kuipers, B., Cullen, W.R., Mohn, W.W., 2002. Sequential anaerobic-aerobic treatment of soil contaminated with weathered aroclor 1260. Environmental Science and Technology. 36 (1), 100-103.

Matamoros, V., Nguyen, L.X., Arias, C.A., Salvadó, V., Brix, H., 2012. Evaluation of aquatic plants for removing polar microcontaminants: a microcosm experiment. Chemosphere. 88 (10), 1257-1264.

Matamoros, V., Rodríguez, Y., Albaigés, J., 2016. A comparative assessment of intensive and extensive wastewater treatment technologies for removing emerging con`aminants in small communities. Water Research. 88, 777-785.

Matamoros, V., Rodríguez, Y., Bayona, J.M., 2017. Mitigation (f el erging contaminants by full-scale horizontal flow constructed wetlands fed with s: Engineering. 99, 222-227.

Matamoros, V., Salvadó, V., 2012. Evaluation of th s. ısr nal performance of a water reclamation pondconstructed wetland system for removir. r er erging contaminants. Chemosphere. 86 (2), 111-117.

Nivala, J., Kahl, S., Boog, J., Afferden, M. Reemtsma, T., Müller, R.A., 2019. Dynamics of emerging organic contaminant removal in cur ve ıtional and intensified subsurface flow treatment wetlands. Science of the Total Environı ıen. 649, 1144-1156.

Petrie, B., Rood, S., Smith, P D., Proctor, K., Youdan, J., Barden, R., Kasprzyk-Hordern., B., 2018. Biotic phase mi op vllut unt distribution in horizontal sub-surface flow constructed wetlands.

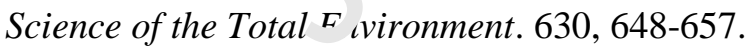

Reyes-Contreras, C., Hijosa-Valsero, M., Sidrach-Cardona, R., Bayona, J.M., Bécares, E., 2012. Temporal evolution in PPCP removal from urban wastewater by constructed wetlands of different configuration: a medium-term study. Chemosphere. 88, 161-167.

Sgroi, M., Pelissari, C., Roccaro, P., Sezerino, P.H., García, J., Vagliasindi, F.G.A., Ávila, C., 2018. Removal of organic carbon, nitrogen, emerging contaminants and fluorescing organic matter in different constructed wetland configurations. Chemical Engineering Journal. 332, 619-627. 
Sultana, M-Y., Akratos, C.S., Vayenas, D.V., Pavlou, S., 2015. Constructed wetlands in the treatment of agro-industrial wastewater: A review. Hemijska industrija. 69 (2), 127-142.

Töre, G.Y., Meriç, S., Lofrano, G., Feo, G.D., 2012. Removal of Trace Pollutants from Wastewater in Constructed Wetlands. Lofrano, G., (Editor), Emerging Compounds Removal from Wastewater, Natural and Solar based Treatment. Springer Dordrecht Heidelberg New York London. pp (39-58). DOI 10.1007/978-94-007-3916-1.

Turon, C., Comas, J., Alemany, J., Cortés, U., Poch, M., 2007. Enviror mental decision support systems: A new approach to support the operation and maintenan $\mathrm{e} f \mathrm{f}$ horizontal subsurface flow constructed wetlands. Ecological Engineering. 30 (4), 362-3/2.

Verlicchi, P., Galletti, A., Petrovic, M., Barceló, D., Al Av:Ay, M., Zambello, E., 2013. Removal of selected pharmaceuticals from domestic wastewater in an activated sludge system followed by a horizontal subsurface flow bed-analysis of the $r$ spective contributions. Science of the Total Environment. 454-455, 411-425.

Verlicchi, P., Zambello, E., 2014. How el. cient are constructed wetlands in removing pharmaceuticals from untreated and treated urban $w^{\prime}$ st : waters? A review. Science of the Total Environment. 470$471,1281-1306$.

Verlicchi, P.; Zambello, E.; ^ ıkic,; M.A., 2015. Removal of Personal Care Products in Constructed Wetlands. In Per. nn ' C r re Products in the Aquatic Environment; Díaz-Cruz, M.S., Barceló, D., Eds.; The Handboc ${ }^{1}$ of Environmental Chemistry; Springer: Cham, Switzerland; Volume 36, pp. 319-354.

Vo, H-N-P., Bui, X-T., Nguyen, T-M-H., Koottatep, T., Bandyopadhyay, A., 2018. Insights of the Removal Mechanisms of Pharmaceutical and Personal Care Products in Constructed Wetlands. Current Pollution Reports. 4 (2), 93-103.

Vymazal, J., 2005. Horizontal subsurface flow and Hybrid constructed wetlands systems for wastewater treatment. Ecological Engineering. 25, 478-490. 
Vymazal, J., 2013. The use of hybrid constructed wetlands for wastewater treatment with special attention to nitrogen removal: a review of a recent development. Water Research. 47 (14), 4795-4811.

Vymazal, J., Březinová, T., Koželuh, M., 2015. Occurrence and removal of estrogens, progesterone and testosterone in three constructed wetlands treating municipal sewage in the Czech Republic. Science of the Total Environment. 536, 625-631.

Vymazal, J., Březinová, T.D., Koželuh, M., Kule, L., 2017. Occurrence and removal of pharmaceuticals in four full-scale constructed wetlands in the Czech Repub'ic-the first year of monitoring. Ecological Engineering. 98, 354-364.

Vystavna, Y., Frkova, Z., Marchand, L., Vergeles, Y., Stolb rg, F., 2017. Removal efficiency of pharmaceuticals in a full scale constructed wetland in ${ }_{-}^{-} \mathrm{sl}$ ' $T$ kraine. Ecological Engineering. 108, $50-58$.

Yi, X., Tran, N.H., Yin, T., He, Y., Gin, K.Y-H., 20`7. ¿e' loval of selected PPCPs, EDCs, and antibiotic resistance genes in landfill leachate by a fv 1 -scale constructed wetlands system. Water Research. $121,46-60$.

Zhang, D., Gersberg, R.M., Ng, W.J., I a ı, ,.K., 2014. Removal of pharmaceuticals and personal care products in aquatic plant-bas d s, 'stems: a review. Environmental Pollution. 184, 620-639.

Zhang, D.Q., Gersberg, R.M. Hu., T., Zhu, J.F., Goyal, M.K., Ng, W.J., Tan, S.K., 2013. Fate of pharmaceutical c mp unc s in hydroponic mesocosms planted with Scirpus validus. Environmental Pollution. 181, 98-1nf.

Zhang, D.Q., Hua, T., Gersberg, R.M., Zhu, J., Ng, W.J., Tan, S.K., 2012. Fate of diclofenac in wetland mesocosms planted with Scirpus validus. Ecological Engineering. 49, 59-64. 


\section{Declaration of interests}

$\mathbf{x}$ The authors declare that they have no known competing financial interests or personal relationships that could have appeared to influence the work reported in this paper.

$\square$ The authors declare the following financial interests/personal relationships which may be considered as potential competing interests:

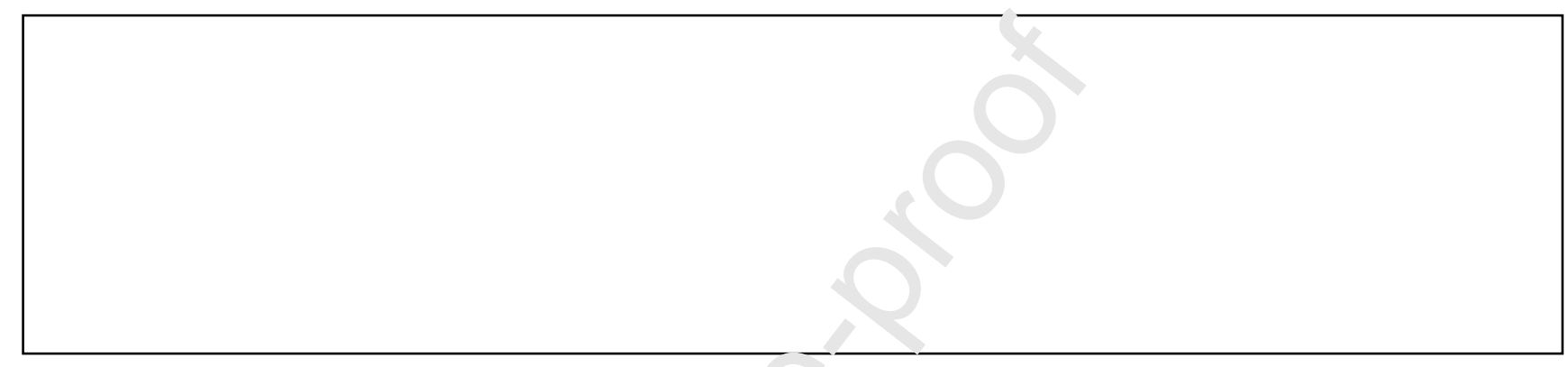




\section{Graphical abstract}

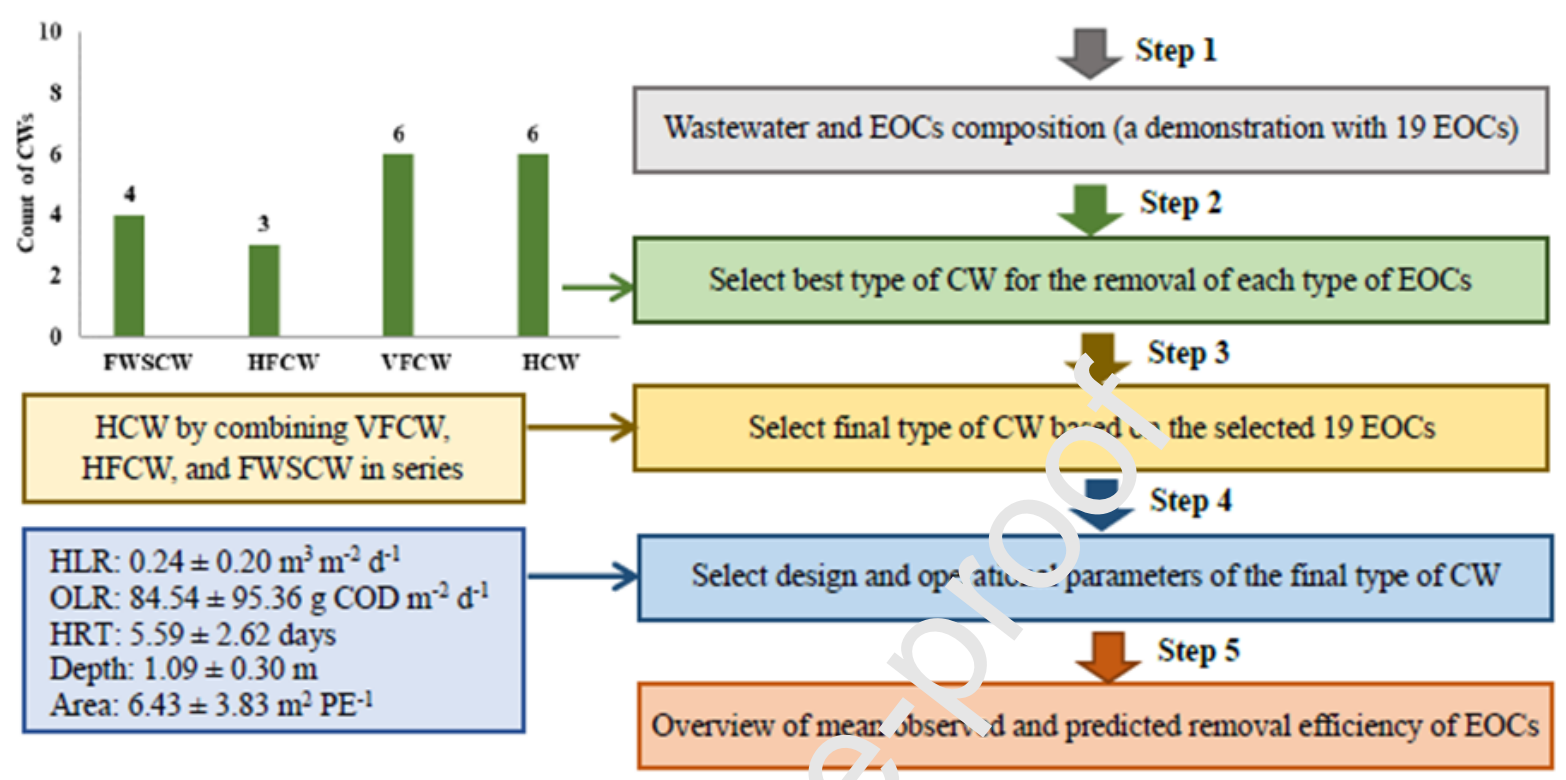




\section{Highlights}

1. A decision tree framework is proposed to support EOCs removal by CWs

2. A data and information-based tool (named as DTFT-CW) is developed for 59 EOCs

3. DTFT-CW provides quick information needed to apply the decision tree framework

4. DTFT-CW provides information for design, operation, and performance of CWs

5. HCW (combining VFCW, HFCW, and FWSCW) is the best for the removal of multiple EOCs 

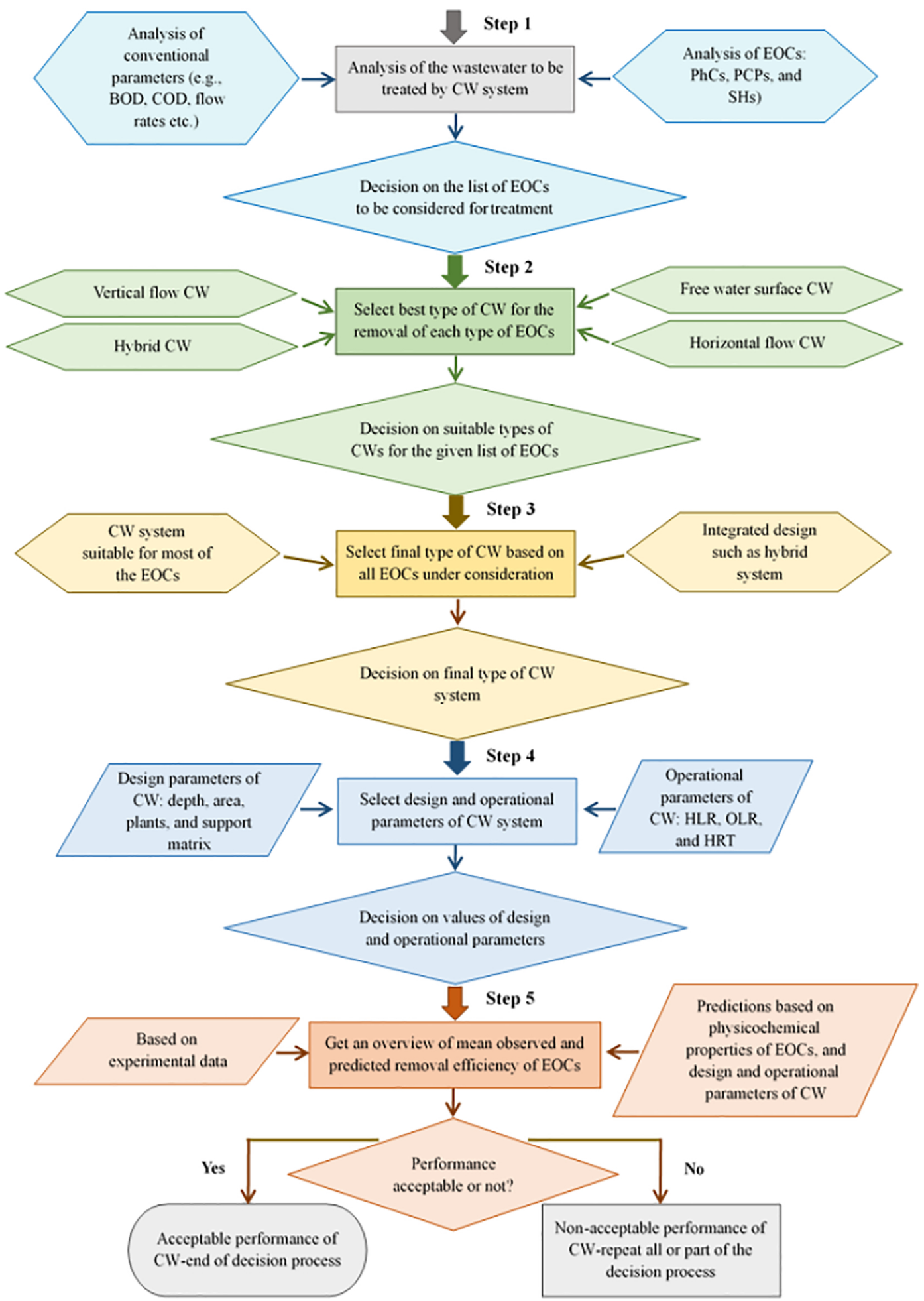
Module 1: Key questions to be answered using this decision

support tool

Module 6: Answers to the questions facilitating discussion and conclusions

Module 5: Overview of predictive models, predicted removal efficiency, analysis of results including comparison between predicted and observed removal efficiency
Module 2: Selection of EOCs and basic data on their environmental risk, physicochemical properties, removal efficiency, and design and operational parameters of CWs

Module 3: Selection of best type of $\mathrm{CW}$ for each $\mathrm{EOC}$, as well as selection of final type of CWs for the removal of multiple types of EOCs

Module 4: Identification of the detailed design and operational features of the proposed $\mathrm{CW}$ system 


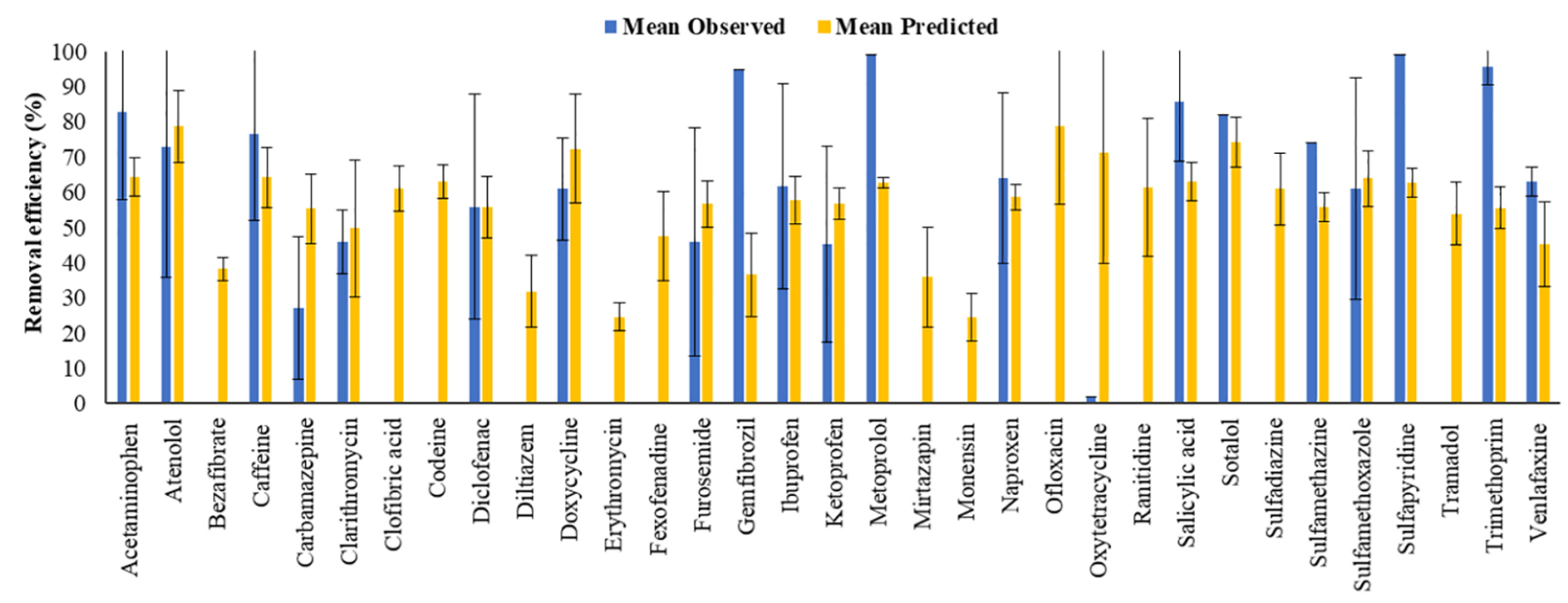

Figure 3 


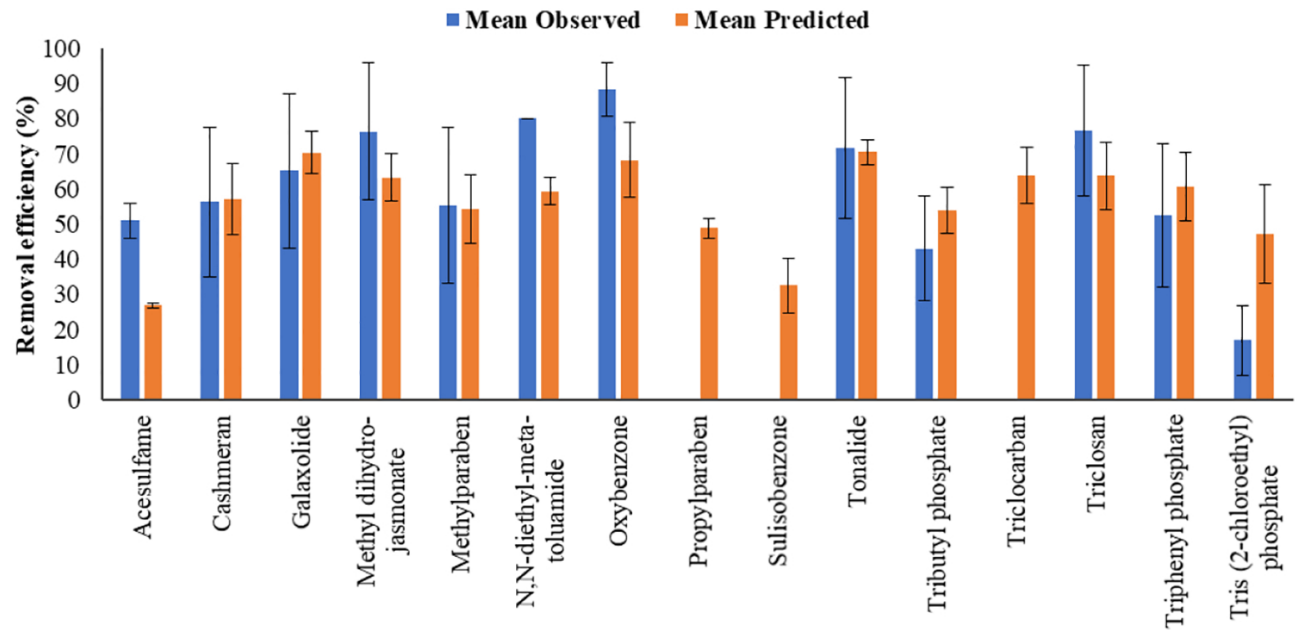

Figure 4 
$\square$ Mean Observed $\square$ Mean Predicted

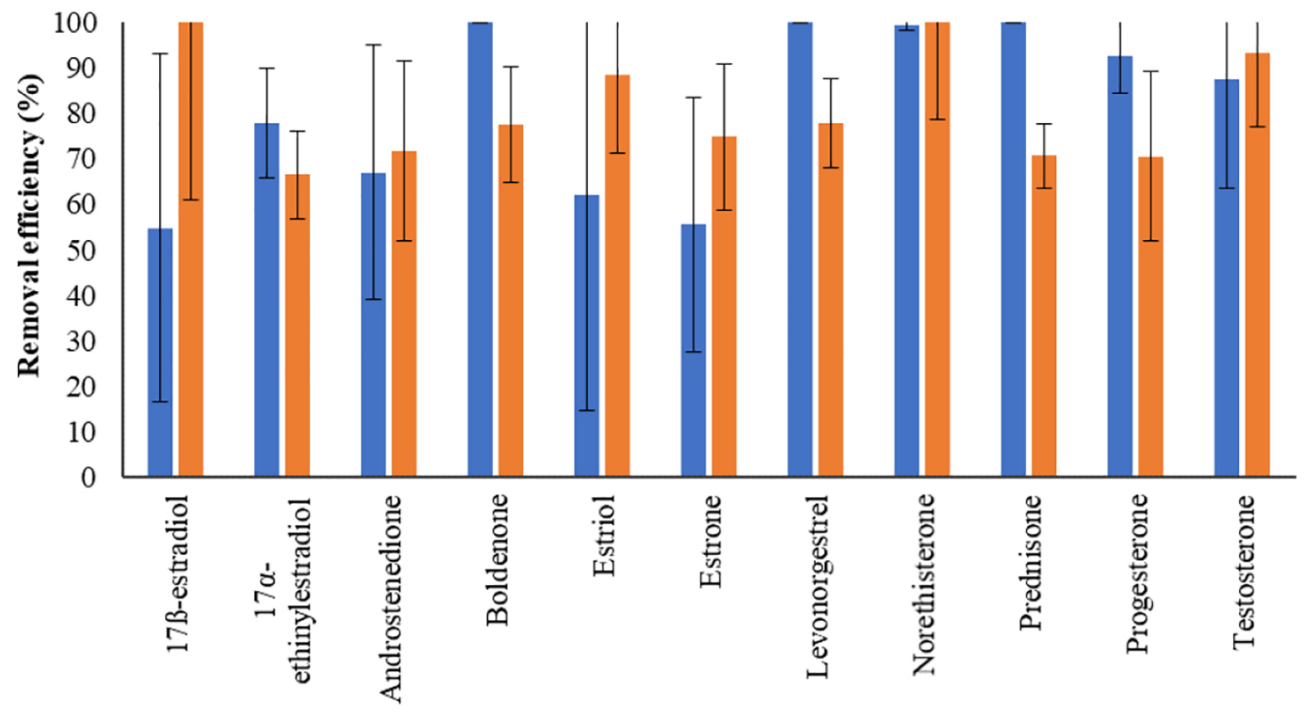

Figure 5 


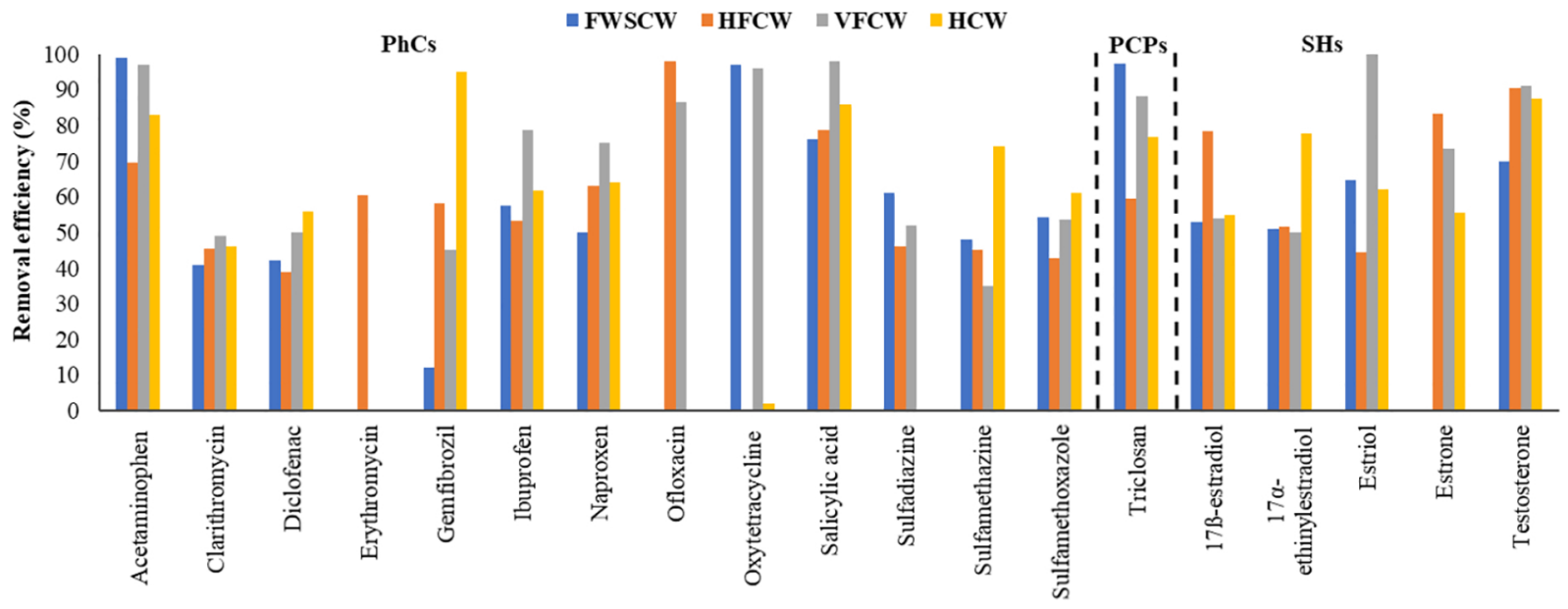

Figure 6 


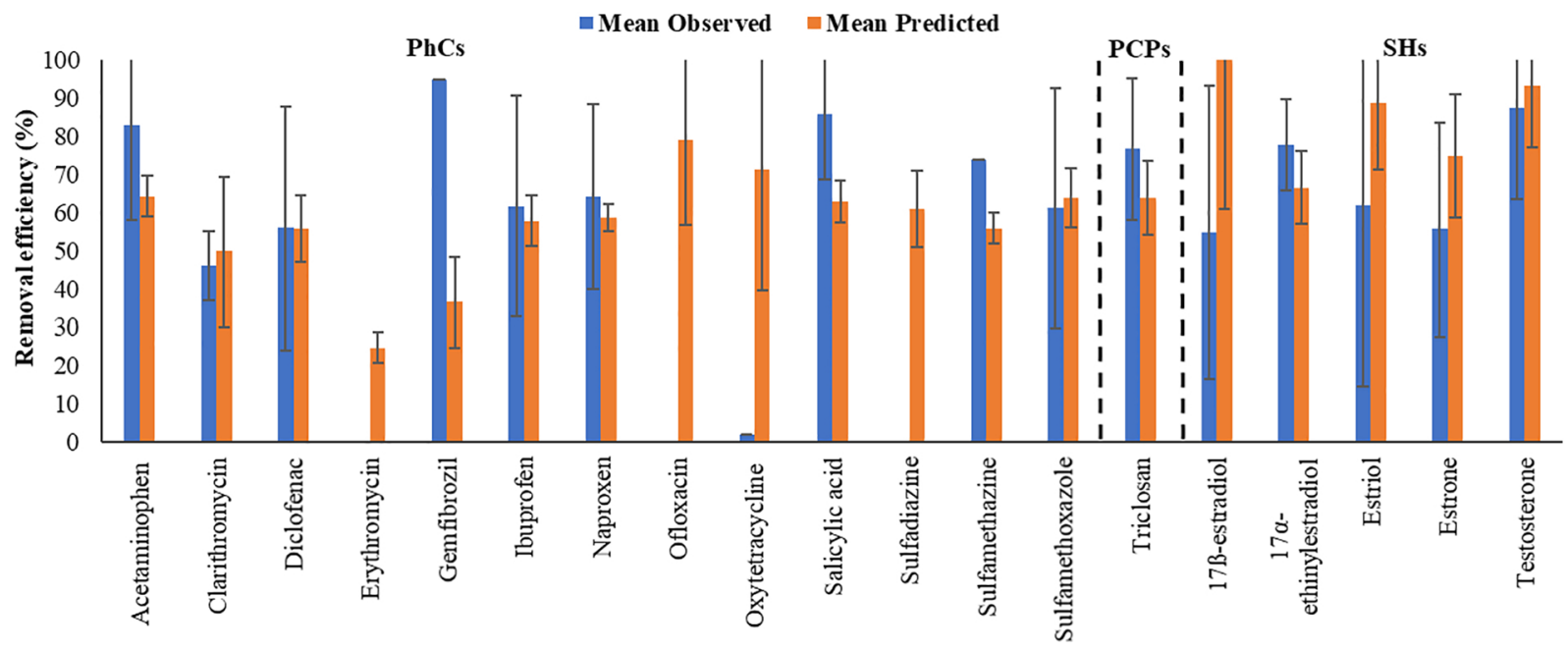

Figure 7 